Article

\title{
Impact of Thermal Dissipation on the Lighting Performance and Useful Life of LED Luminaires Applied to Urban Lighting: A Case Study
}

\author{
Juan de Dios Unión-Sánchez ${ }^{1}$ (D), Manuel Jesús Hermoso-Orzáez ${ }^{1,2, * \mathbb{D}}$, Manuel Jesús Hervás-Pulido ${ }^{2}$ and \\ Blas Ogáyar-Fernández ${ }^{1,3}$
}

check for updates

Citation: Unión-Sánchez, J.d.D.; Hermoso-Orzáez, M.J.;

Hervás-Pulido, M.J.;

Ogáyar-Fernández, B. Impact of

Thermal Dissipation on the Lighting Performance and Useful Life of LED Luminaires Applied to Urban Lighting: A Case Study. Int. J. Environ. Res. Public Health 2022, 19, 752. https://doi.org/10.3390/ ijerph19020752

Academic Editors: Irena Fryc and Tomasz Ściężor

Received: 27 November 2021

Accepted: 7 January 2022

Published: 10 January 2022

Publisher's Note: MDPI stays neutral with regard to jurisdictional claims in published maps and institutional affiliations.

Copyright: (C) 2022 by the authors. Licensee MDPI, Basel, Switzerland. This article is an open access article distributed under the terms and conditions of the Creative Commons Attribution (CC BY) license (https:// creativecommons.org/licenses/by/ $4.0 /)$.
1 Centre for Advanced Studies in Energy and Environment, University of Jaén, 23071 Jaén, Spain; junion@ujaen.es (J.d.D.U.-S.); bogayar@ujaen.es (B.O.-F.)

2 Department of Graphic Engineering, Design and Projects, University of Jaén, 23071 Jaén, Spain; mjhp0001@red.ujaen.es

3 Department of Electrical Engineering, University of Jaén, 23071 Jaén, Spain

* Correspondence: mhorzaez@ujaen.es; Tel.: +34-610-389-020

\begin{abstract}
Currently, LED technology is an established form of lighting in our cities and homes. Its lighting performance, durability, energy efficiency and light, together with the economic savings that its use implies, are displacing other classic forms of lighting. However, some problems associated with the durability of the equipment related to the problems of thermal dissipation and high temperature have begun to be detected, which end up affecting their luminous intensity and the useful life. There are many studies that show a direct relationship between the low quality of LED lighting and the aging of the equipment or its overheating, observing the depreciation of the intensity of the light and the visual chromaticity performance that can affect the health of users by altering circadian rhythms. On the other hand, the shortened useful life of the luminaires due to thermal stress has a direct impact on the LCA (Life Cycle Analysis) and its environmental impact, which indirectly affects human health. The purpose of this article is to compare the results previously obtained, at different contour temperatures, by theoretical thermal simulation of the 3D model of LED street lighting luminaires through the ANSYS Fluent simulation software. Contrasting these results with the practical results obtained with a thermal imaging camera, the study shows how the phenomenon of thermal dissipation plays a fundamental role in the lighting performance of LED technology. The parameter studied in this work is junction temperature $\left(\mathrm{T}_{\mathrm{j}}\right)$, and how it can be used to predict the luminous properties in the design phase of luminaires in order to increase their useful life.
\end{abstract}

Keywords: LED; thermal dissipation; luminaire; CFD (computational fluid dynamics); FMV (finite volume method)

\section{Introduction}

Currently, energy saving in public lighting is generating great interest and has become a priority in the management of outdoor lighting in our cities; for this reason, LED luminaires are becoming more and more frequent [1]. There are studies related to the thermal dissipation of LEDs applied to automotive lighting that systematically prove that the properties of thermal interface materials, such as thermal resistance, affect the optical properties of the luminaire [2]. Other studies demonstrate the loss of chromaticity and degradation of light, the change in chromaticity, and transmittance loss tested in phosphor converted white light emitting diodes (PC-WLED) under accelerated thermal tests at $150{ }^{\circ} \mathrm{C}, 200{ }^{\circ} \mathrm{C}$, and $250{ }^{\circ} \mathrm{C}$ [3]. On the other hand, the increasing use of LED lights has modified the natural light environment dramatically, posing novel challenges to both humans and wildlife. Indeed, several biomedical studies have linked artificial light at night to the disruption of circadian rhythms [4], with important consequences for human health, 
such as the increasing occurrence of metabolic syndromes [5], cancer [6], and reduced immunity [7]. In this sense, there are many studies that clearly show the adverse effects of poor lighting on health, including light depreciation as a consequence of deterioration, faulty thermal dissipation, or the devaluation of the light intensity and chromaticity of the luminaire [8,9].

The chromaticity, electrical properties and thermal properties of LED devices are highly dependent on each other [10]; therefore, heat dissipation plays an important role in improving the efficiency and reliability of LED lighting [11]. Deficiencies in artificial lighting, loss of light intensity, or changes in chromaticity can have serious consequences on human health in relation to circadian rhythms $[12,13]$. This is why it is extremely important to install energy-efficient outdoor lighting equipment, but that have, at the same time, a low impact on human health $[14,15]$. Shorter wavelengths of light preferentially disturb melatonin secretion and cause circadian phase shifts, even if the light is not bright [13].

The main source of heat in an LED comes from the union between the p-type and the n-type semiconductor material that makes up the device [16]. The LEDs disperse $45 \%$ of the energy applied in light and the remaining 55\% in heat. High-power chips increasingly emit more heat, which leads to performance degradation [17] and, ultimately, results in a shorter life expectancy of LED products. Therefore, the industry is investigating product design structures to control the heat generated by high power LED chips [18].

The temperature reached at the $p-n$ junction is called junction temperature $\left(T_{j}\right)$ and is considered a key parameter in LED performance [19]. The junction temperature at which light-emitting diodes have to operate must be low, as there is an inverse relationship between junction temperature and the lifetime of the LED [20].

The internal thermal resistance and junction temperature $\left(T_{j}\right)$ are the critical parameters of LEDs, which must be maintained at nominal levels for reliable and robust operation [21].

For a given set of operating conditions, an engineer can calculate the junction temperature of an LED [22] and design a thermal dissipation system to lower the temperature of electronic devices and extend the life of LEDs [23].

Modern chips are designed with conductive heat pipes to channel heat from the junction to the "solder point". The welding point is the part of the LED that comes in contact with the PCB (printed circuit board) and/or independent heat sink.

The object of this study is to propose an analysis methodology to calculate the theoretical thermal dissipation, a priori, depending on the design, the materials and the operating ambient temperature of the LED luminaires to later compare and discuss the theoretical results with the experimental ones made with a thermographic camera. The comparison of results between the simulations and the real dissipation in the laboratory allow to analyze the junction temperature of the LEDs because it is a parameter that cannot be measured through a thermographic camera. To do this, we thermally analyze, according to the proposed method, a LED luminaire, carrying out simulations, at different working environment temperatures [24]. Considering that thermal dissipation is essential to maintain the luminous properties of LED luminaires, directly impacting the useful life of the equipment and its light quality [25], in direct relation to the impact that these deficiencies can have on the circadian rhythms of people exposed to the light artificial defective [26,27]. Likewise, the useful life of LED luminaires is related to the quality of the equipment and the ability of the materials to dissipate radiated heat, this aspect directly impacting the LCA (life cycle analysis) on the carbon footprint [28] and environmental impacts of the manufacture of new substitute equipment $[25,29]$. Today, it is very important to invest on sustainable luminaires with a low carbon footprint and high durability [28].

\section{Methodology}

The methodology applied in this work has two parts. First, a simulation of the thermal dissipation of a LED luminaire model applied to urban lighting under different boundary conditions was carried out. 
The Model luminaire corresponds to a high-power LED luminaire with a specific design to achieve an adequate lighting performance and optimal thermal dissipation. We proceeded to analyze the results and observe the theoretical heat dissipation that occurs in it using the ANSYS Fluent software [30].

Later, this work is complemented with a validation analysis of the methodology with the practical results realized with a thermographic camera. We analyzed the actual results of the thermal dissipation of the luminaire with respect to the boundary conditions in the lighting laboratory [31], trying to assess and contrast the theoretical results, expected a priori in the design phase, with the real and practical results obtained [32]. We will try to justify that an adequate design and the choice of materials are key elements that allow a better heat dissipation in LED luminaires, improving their stability and lighting performance [33].

The analysis through CFD (computational fluid dynamics) simulation is represented in Figure 1, through which we obtained the theoretical results of the thermal dissipation that were produced by the Model and thus be able to make the comparison between the data obtained between the theoretical simulations and the experimental data obtained with the thermal imaging camera [34].

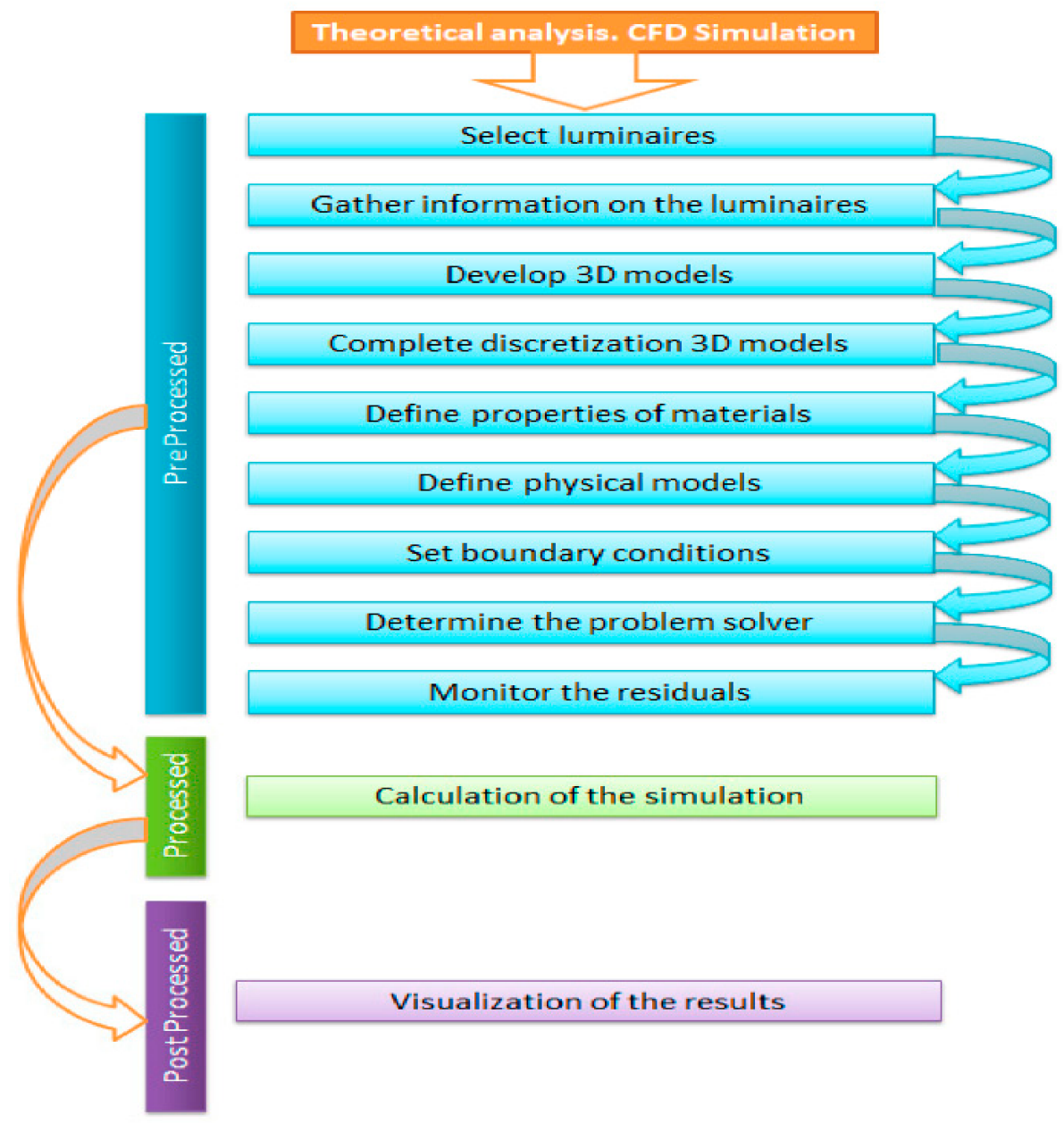

Figure 1. Flow diagram for the analysis of theoretical thermal dissipation. Source: our own elaboration.

The computational dynamics of fluids is the science that predicts the flow of a fluid, the transfer of heat and mass, chemical reactions, and related phenomena through the numerical resolution of the set of mathematical equations.

CFD analysis complements testing and experimentation by reducing the total effort and cost required for experimentation and data acquisition. 
In the numerical simulation, there are three stages: pre-processed, processed and post-processed.

\subsection{Pre-Processing}

\subsubsection{Select the Luminaires for the Study}

The study was carried out by selecting a high-power luminaire manufactured with a novel design, specially oriented to the improvement of the thermal dissipation, and is referred to as Model.

\subsubsection{Obtaining the Information on the Luminaire to Be Analyzed}

The manufacturer provided the different characteristics and properties of the luminaire, who remains confidential in this project.

The Model consists of different components and materials that are attached in Table 1. The total nominal power of the luminaire is $204 \mathrm{~W}$, of which $192 \mathrm{~W}$ is for the operation of the LEDs and $12 \mathrm{~W}$ for the drivers.

The drivers are composed of an electronic circuit that performs the following functions:

- $\quad$ To transform alternating current (AC) into direct current (DC), which is used by LEDs for their correct operation;

- $\quad$ To adapt the output voltage and current to the LED requirements.

Table 1. Components, materials and powers. Source: ATP lighting S.A.

\begin{tabular}{ccccc}
\hline Components & Subcomponent & Part & Material & Information \\
\hline Cover & - & - & PC & Opaque \\
Heatsink & - & - & Aluminum & Confidential \\
Equipment carrier & - & - & PA66-30FV & - \\
Equipment & - & - & PA66-30FV & - \\
& Microchips & Silicon & Tin drivers; 6 W/driver \\
Drivers & PCB driver & Welding & Aluminum & Transparent \\
& Housing & Base & PC & - \\
Diffuser & - & - & PA66-30FV & - \\
Chassis & - & - & Aluminum & 96 LED; 2 W/LED \\
PCB LED & - & - & Copper/Material Rth & 96.
\end{tabular}

\subsubsection{Elaboration of the 3D Model of the Equipment}

The elaboration of the model was carried out using CATIA (Computer-Aided ThreeDimensional Interactive Application) [35], which consists of computer-aided design, manufacturing and engineering software (Figure 2).

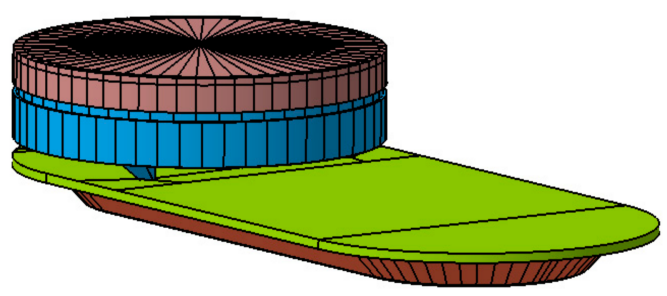

Figure 2. Modelling in 3D of the luminaire Model. Source: our own elaboration.

\subsubsection{Discretization of the 3D Model for Study}

To execute the discretization, the specific program Altair HyperMesh was used. It is a computer-aided engineering simulation software (CAE, computer aided engineering) platform, in which it is possible to create finite element models for the analysis and prepare 
meshes of high quality efficiently. The method of discretization in the 3D model was in finite volumes [36].

A two-dimensional mesh was made with triangular elements (triads). Having a control of the mesh with skew means that an angle between the vector from each node to the midpoint of the opposite side and the vector between the two adjacent middle sides in each node of the element is 90 degrees minus the angle found using skew. In this study, the skew sought is 60 degrees, providing a triangle as similar as possible to an equilateral triangle for the subsequent generation of 3D elements. See Figures 3 and 4.

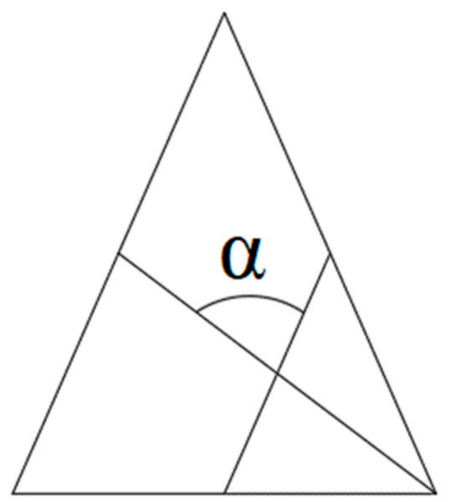

Figure 3. Definition of skew. Source: HyperMesh meshing control guide.

\begin{tabular}{|l|c|c|}
\hline BEST & OK & VERY POOR \\
\hline & \\
\hline
\end{tabular}

Figure 4. Mesh control. Source: HyperMesh meshing control guide.

Luminaire Discretization Model

Next, in the series of Figures 5-7, we represent the discretized components.

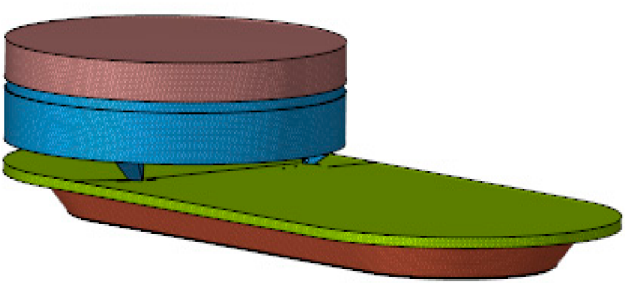

Figure 5. Discretized luminaire Model. Source: our own elaboration from the software HyperMesh. 


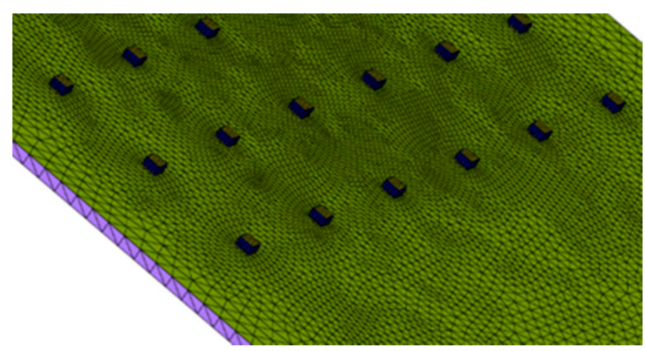

Figure 6. Discretized PCB and LED diode. Source: our own elaboration from the software HyperMesh.

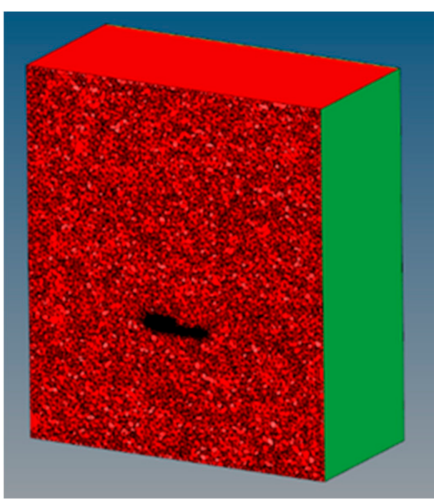

Figure 7. Average section of the components and air generated with tetrahedral Model. Source: our own elaboration from the software HyperMesh.

The mesh was generated in triads and a tetrahedral, although with square meshes and hexahedrons can be provided higher quality solutions with fewer cells/nodes. The square and hexahedral meshes show a reduced numerical diffusion when the mesh is aligned with the flow, but more effort is also required in generating a square mesh and hexahedrons.

\subsubsection{Configuration of the Physical and Solver Characteristics}

Definition of the Properties of Materials

It is necessary to define the properties of the materials that are going to be assigned to the different components of the luminaire to be taken into account during the study and thus have greater precision in the results when compared with the experimental data, reflected in Table 2.

Table 2. Properties of the materials of the model. Source: commercial catalogs of the manufacturer's Model (ATP).

\begin{tabular}{|c|c|c|c|}
\hline Material & $\begin{array}{l}\text { Density } \\
\mathrm{kg} / \mathrm{m}^{3}\end{array}$ & $\begin{array}{l}\text { Specific Heat } \\
\mathrm{J} / \mathrm{kg} \cdot \mathrm{K}\end{array}$ & $\begin{array}{l}\text { Thermal Conductivity } \\
\mathrm{W} / \mathrm{m} \cdot \mathrm{K}\end{array}$ \\
\hline Aluminum & 2750 & 961 & 200 \\
\hline Silicon & 2330 & 700 & 148 \\
\hline Tin & 7365 & 228 & 66.6 \\
\hline PA66-30FV & 1370 & 2290 & 0.29 \\
\hline PC & 1200 & 1250 & 0.19 \\
\hline Copper & 8900 & 394 & 387 \\
\hline Material Rth & 3300 & 780 & 52.91 \\
\hline
\end{tabular}

The thermal resistance of the LED (Rth) of the luminaire of Model is $2.1 \mathrm{~W} / \mathrm{K}$.

Definition of Physical Models

1. Conservation equations.

The ANSYS Fluent solver is based on the finite volume method [37]. The domain is discretized in a finite set of control volumes and the general conservation equations for 
mass, momentum, energy, etc., are solved in this set of control volumes. All the equations are then solved numerically to represent the solution field.

\section{Finite Volume Method.}

The general equations of conservation of the mass, amount of movement, energy, etc. are resolved in this set of control volumes. In the centroid of each control volume, there is a node where the value of the variables is calculated and, in the borders, their value can be known through interpolation. Then, we continued with an approximation of the conservation equations to determine a system of algebraic equations and obtain their solution by iterative methods.

Starting from the general transport equation, obeying the Navier-Stokes equations in the integral form [38]:

$$
\frac{\mathrm{d}}{\mathrm{dt}} \int_{\mathrm{V}} \rho \Phi \mathrm{dV}+\oint_{\mathrm{A}} \rho \overrightarrow{\mathrm{v}} \Phi \cdot \overrightarrow{\mathrm{n}} \mathrm{dA}=\oint_{\mathrm{A}} \rho \Gamma \nabla \Phi \cdot \overrightarrow{\mathrm{n}} \mathrm{dA}+\int_{\mathrm{V}} \mathrm{S}_{\phi} \mathrm{dV},
$$

where

$\Phi=$ variable transported by a medium;

$\rho=$ density of the medium through which it is transported $\Phi$;

$\mathrm{V}=$ travel speed of $\Phi$ through the medium;

$\Gamma=$ medium diffusion constant;

$S_{\phi}=$ source/sink term of the variable transported;

$\mathrm{A}=$ border;

$\overrightarrow{\mathrm{v}}=$ speed vector of $\Phi$ through the medium;

$\vec{n}=$ normal vector to the surface.

The first term corresponds to the temporal variation of the variable transported by the medium within a volume; the second term corresponds to the convective flows of the variable transported across the border due to the speed. The first term after equality expresses the diffusive term of the variable transported at the border that depends only on the gradient of said variable, and the last term is due to the source term of the variable inside the volume.

The source term, $S_{\phi}$ of Equation (1), contains the radiation terms calculated through the discrete ordinate model (DO). The DO model transforms the radioactive transport equation for an absorption, emission and dissipation medium in the position $\vec{r}$ and in the direction $\vec{s}$ in a transport equation for the radiation intensity in the spatial coordinates $(x$, $\mathrm{y}, \mathrm{z})$. The resolution method is the same as that used for the flow and energy equations, and represented in Equation (2) [38]:

$$
\frac{\mathrm{dI}(\overrightarrow{\mathrm{r}}, \overrightarrow{\mathrm{s}})}{\mathrm{ds}}+\left(\mathrm{a}+\sigma_{\mathrm{s}}\right) \mathrm{I}(\overrightarrow{\mathrm{r}}, \overrightarrow{\mathrm{s}})=\mathrm{an}^{2} \frac{\sigma \mathrm{T}^{4}}{\pi}+\frac{\sigma_{\mathrm{s}}}{4 \pi} \int_{0}^{4 \pi} \mathrm{I}\left(\overrightarrow{\mathrm{r}}, \overrightarrow{\mathrm{s}}^{\prime}\right) \Phi\left(\overrightarrow{\mathrm{s}} \cdot \overrightarrow{\mathrm{s}}^{\prime}\right) \mathrm{d} \Omega^{\prime}
$$

where

$\overrightarrow{\mathrm{r}}=$ position vector;

$\overrightarrow{\mathrm{s}}=$ direction vector;

$\overrightarrow{\mathrm{s}}^{\prime}=$ vector direction dissipation;

$\mathrm{s}=$ path length;

$\mathrm{a}=$ absorption coefficient;

$\mathrm{n}=$ refractive index;

$\sigma_{\mathrm{s}}=$ dispersion coefficient;

$\sigma=$ Constant Stefan-Boltzmann $\left(5669 \times 10^{-8} \mathrm{~W} / \mathrm{m}^{2} \mathrm{~K}^{4}\right)$;

$\mathrm{I}=$ Intensity of radiation;

$\mathrm{T}=$ local temperature in Kelvin;

$\Phi=$ phase function; 
$\Omega^{\prime}=$ solid angle

For finite volumes and sub-border volumes that correspond to the volume boundary, we obtained [38]:

$$
\mathrm{V}_{\text {cell }} \cdot \frac{\partial \Phi}{\partial \mathrm{t}}+\sum_{\mathrm{f}}^{\text {Nfaces }} \rho_{\mathrm{f}} \overrightarrow{\mathrm{V}}_{\mathrm{f}} \Phi_{\mathrm{f}} \cdot \overrightarrow{\mathrm{A}}_{\mathrm{f}}=\sum_{\mathrm{f}}^{\text {Nfaces }} \Gamma_{\phi} \nabla \Phi_{\mathrm{f}} \cdot \overrightarrow{\mathrm{A}}_{\mathrm{f}}+\mathrm{S}_{\phi}+\mathrm{V}_{\text {cell }}
$$

where

$\mathrm{N}_{\text {faces }}=$ number of faces of volume;

$\mathrm{f}=$ fluid

The differential equations were discretized in a system of algebraic equations that are solved numerically to give a field of solutions.

Implement boundary conditions

The boundary conditions were determined to study the behavior of the luminaire in certain cases. The boundary conditions were determined in the air, which is found surrounding the luminaire. Several environmental temperatures have been attempted to be simulated [24], such as, $40{ }^{\circ} \mathrm{C}, 20^{\circ} \mathrm{C}$ and $-10{ }^{\circ} \mathrm{C}$, with an initial speed ascending of $0.02 \mathrm{~m} / \mathrm{s}$.

3. Determination of the problem solver.

ANSYS Fluent allows one to choose one of the two numerical methods:

- Pressure-based solver;

- Density-based solution.

In both methods, the velocity field is obtained from the moment equations. In the density-based approach, the continuity equation is used to obtain the density field, while the pressure field is determined from the state equation.

On the other hand, in the pressure-based approach, the pressure field is extracted by solving a pressure or pressure correction equation that is obtained by manipulating the continuity and momentum equations.

In our case, we used the pressure-based solver, which uses an algorithm that belongs to a general class of methods, called the projection method.

There are two pressure-based solution algorithms available in ANSYS Fluent. A segregated algorithm and a coupled algorithm.

- $\quad$ Segregated algorithm based on pressure: The individual governing equations for the solution variables (for example, $\mathrm{u}, \mathrm{v}, \mathrm{w}, \mathrm{p}, \mathrm{T}, \mathrm{k}$, etc.) are solved one after the other. The convergence of the solution is relatively slow, since the equations are resolved in an uncoupled way;

- $\quad$ Algorithm coupled based on pressure: The pressure-based coupled algorithm solves a coupled system of equations that comprises the moment equations and the pressurebased continuity equation. Since the equations of momentum and continuity are solved in a tightly coupled manner, the convergence rate of the solution improves significantly compared to the segregated algorithm. The convergence with this algorithm improves with respect to the segregated algorithm, which is taken into account in the choosing of this method.

4. Monitorization of residuals.

In a CFD analysis, the residue measures the local imbalance of a variable stored in each control volume. For CFD, the residual levels of $10^{-4}$ are considered to be slightly convergent, the levels of $10^{-5}$ are considered to be very convergent, and the levels of $10^{-6}$ are considered to be closely convergent. 


\subsection{Processed}

The residual definitions that are useful for a problem class are sometimes deceptive for other kinds of problems. Therefore, it is a good idea to judge convergence not only by examining residual levels, but also by monitoring relevant integrated quantities, such as the heat transfer or drag coefficient.

In the present analysis, continuity, velocity in $x$, velocity in $y$, velocity in $z$, energy and DO with a convergence criterion $10^{-3}, 10^{-3}, 10^{-3}, 10^{-3}, 10^{-6}$ and $10^{-5}$ were taken into account, respectively.

\subsection{Post-Processing}

The results were examined to review the solution and extract the data. The tool used is Altair HyperView, a complete post-processing and visualization environment for CFD. It allows to visualize the data in an interactive way.

\section{Results}

The results section is divided into two parts. On the one hand, the theoretical results show the data obtained with the simulation software at the three boundary temperatures, as well as the validation of the luminaire materials by comparing the limit temperatures of each of the materials that make up the luminaires with the operating temperatures obtained in the simulation for each of them.

Finally, in the practical results, the thermal dissipation of the LED luminaire is tested at an ambient temperature of $20^{\circ} \mathrm{C}$ in order to validate the theoretical results obtained previously.

\subsection{Theoretical Results}

3.1.1. Display of Temperature and Air Speed in the Model Luminaire at $20^{\circ} \mathrm{C}$

In the next Figures 8 and 9, we graphically display in color the temperature of different parts of the Model at $20^{\circ} \mathrm{C}$.

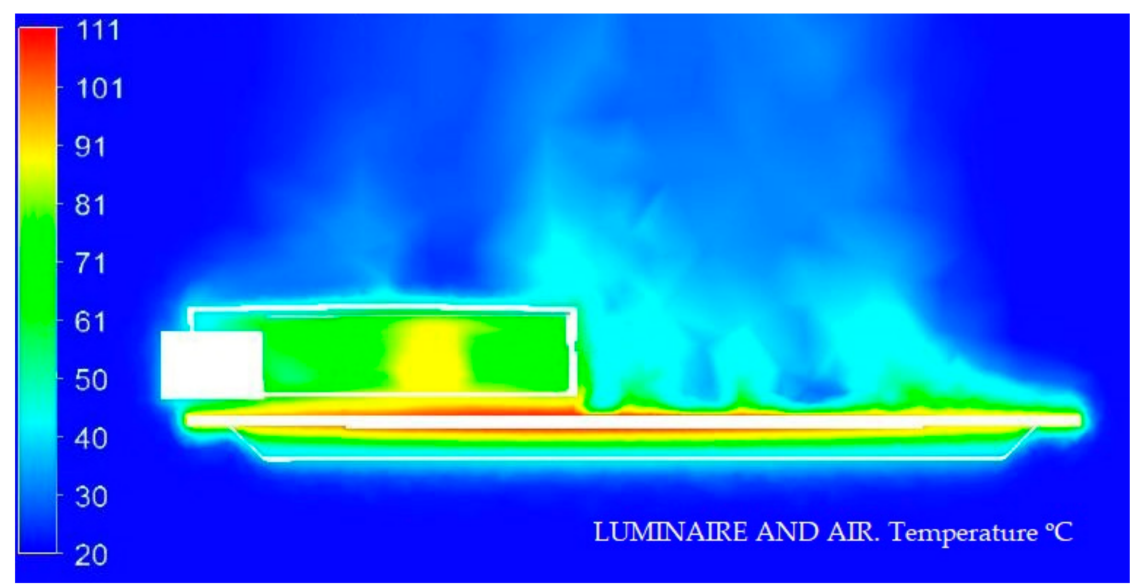

Figure 8. Temperature medium section of the luminaire at $20^{\circ} \mathrm{C}$. Source: HyperView software. 


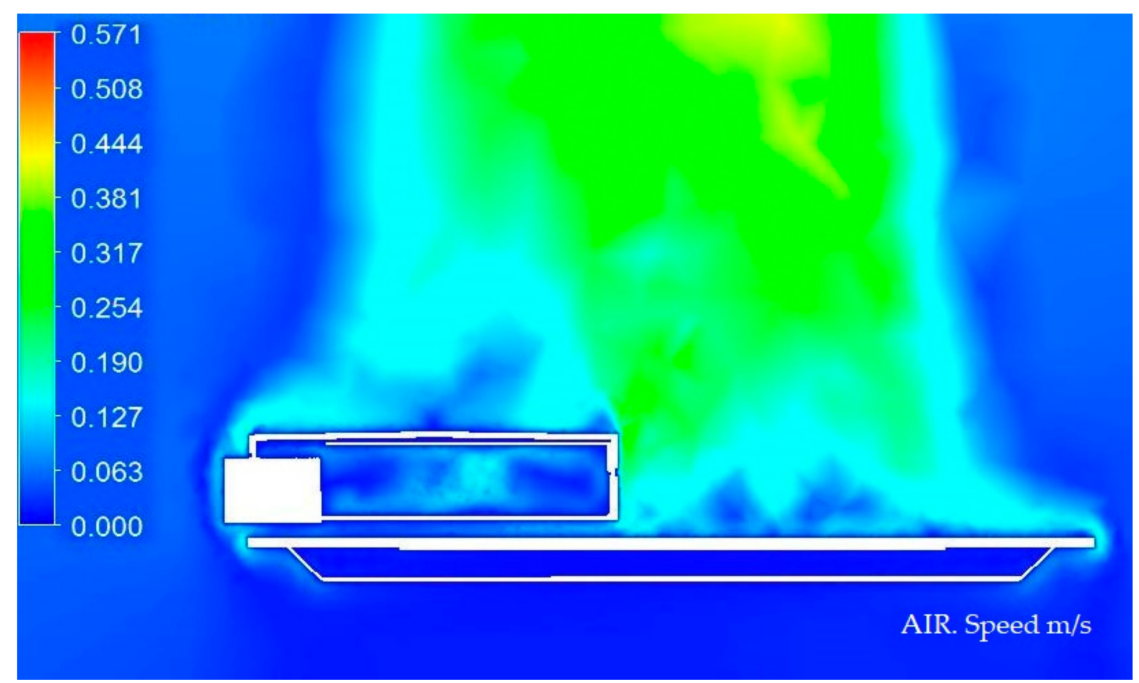

Figure 9. Speed section medium of the luminaire at $20^{\circ} \mathrm{C}$. Source: HyperView software.

3.1.2. Display of Temperature and Air Speed in the Model Luminaire at $40{ }^{\circ} \mathrm{C}$

In the next Figures 10 and 11, we graphically display in color the temperature of different parts of the Model at $40{ }^{\circ} \mathrm{C}$.

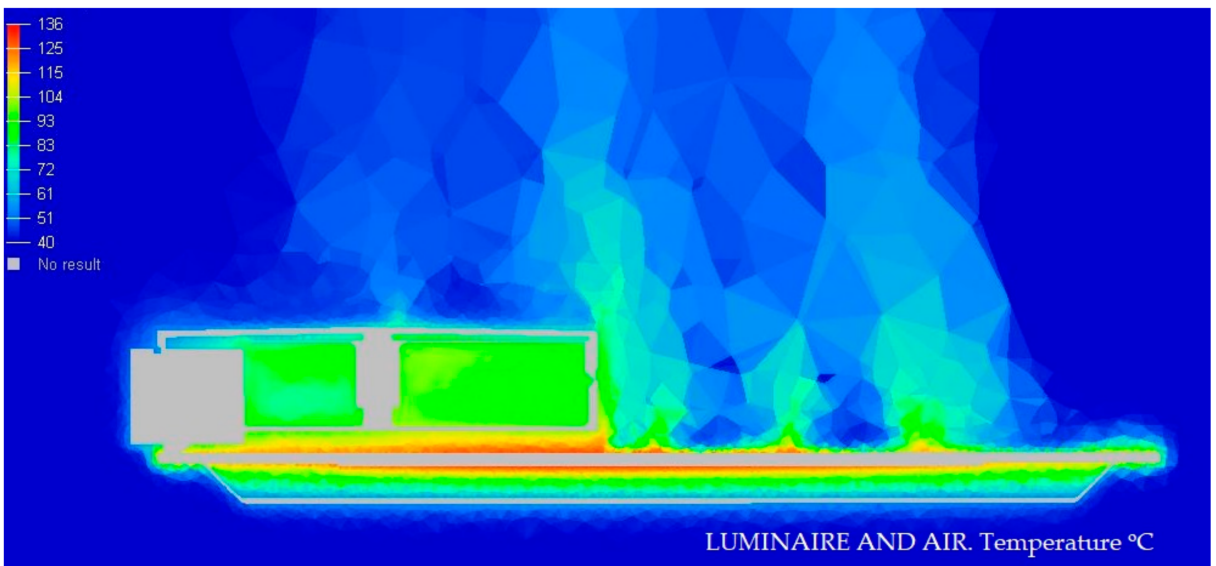

Figure 10. Temperature medium section of the luminaire at $40^{\circ} \mathrm{C}$. Source: HyperView software.

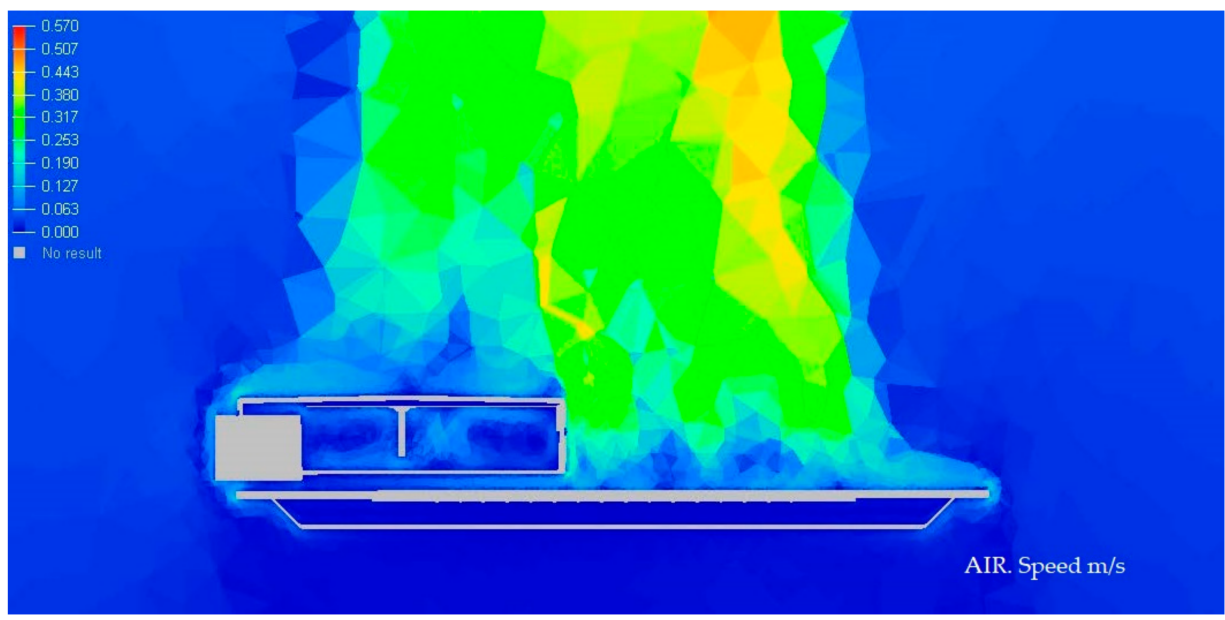

Figure 11. Speed section media of the luminaire at $40^{\circ} \mathrm{C}$. Source: HyperView software. 
3.1.3. Display of Temperature and Air Speed in the Model Luminaire at $-10{ }^{\circ} \mathrm{C}$

In the next Figures 12 and 13, we graphically display in color the temperature of different parts of the Model at $-10^{\circ} \mathrm{C}$.

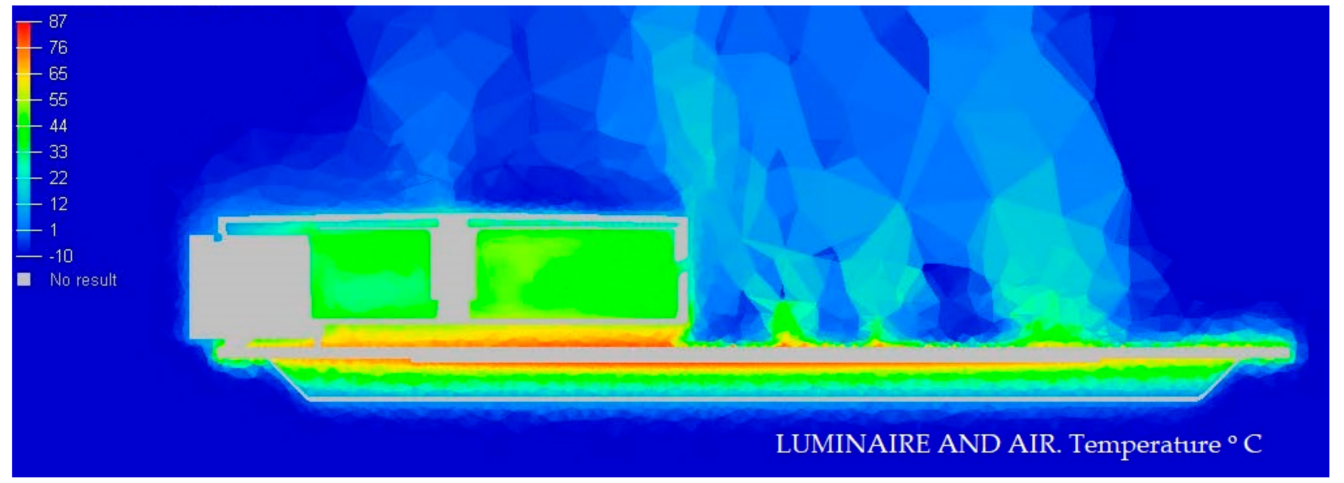

Figure 12. Temperature medium section of the luminaire at $-10^{\circ} \mathrm{C}$. Source: HyperView software.

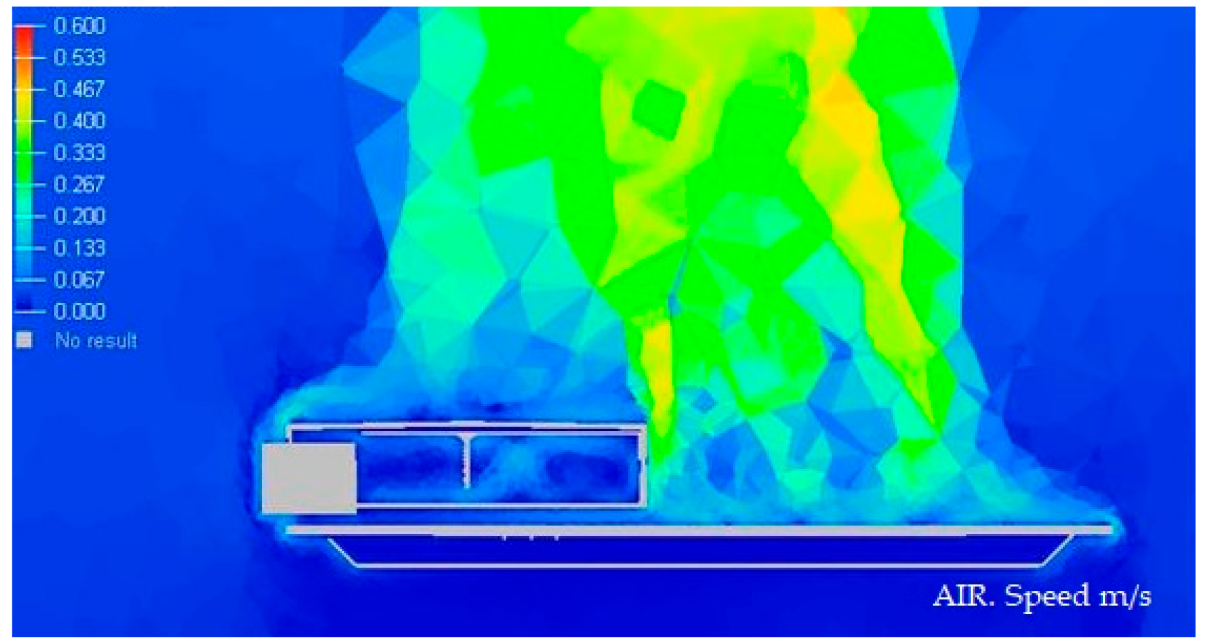

Figure 13. Speed section medium of the luminaire at $-10^{\circ} \mathrm{C}$. Source: HyperView software.

In the theoretical data obtained from the simulations, a validation of the materials is carried out followed by an analysis of the LEDs. The validation of the materials consists of the comparison of the limit temperature that the material used for its operation can reach without having problems of deterioration with the maximum temperature reached in each component of the luminaire to observe if the limit temperature of the material is exceeded.

Regarding the drivers, they are not composed of only one material, as it is a combination of several subcomponents. The weakest components to the temperature are the microchips that are assembled on the driver PCB, then in the comparison we have divided the driver information in two rows (bases and electronics components) and for electronics we select the temperature limit of the microchips for the evaluation of the driver (Tables 3-5). 
Table 3. Maximum temperature limit of the material versus temperature measured in the different parts of the Model at $20^{\circ} \mathrm{C}$. Source: our own elaboration.

\begin{tabular}{|c|c|c|c|}
\hline Component & Material & $\begin{array}{l}\text { Maximum Limit } \\
\text { Temperature }\left({ }^{\circ} \mathrm{C}\right)\end{array}$ & $\begin{array}{c}\text { Temperature } \\
\text { Measured }\left({ }^{\circ} \mathrm{C}\right)\end{array}$ \\
\hline Cover & PC & 145 & 70 \\
\hline Heatsink & Aluminum & 460 & 112 \\
\hline Equipment carrier & PA66-30FV & 150 & 77 \\
\hline Equipment & PA66-30FV & 150 & 112 \\
\hline Drivers Bases & Aluminum & 460 & 112 \\
\hline Driver (Electronic) & Silicon (Weakest) & 150 & 105 \\
\hline Diffuser & PC & 145 & 100 \\
\hline Chassis & PA66-30FV & 150 & 107 \\
\hline PCB & Aluminum & 460 & 117 \\
\hline
\end{tabular}

Table 4. Maximum temperature limit of the material versus temperature measured in the different parts of the Model at $40{ }^{\circ} \mathrm{C}$. Source: our own elaboration.

\begin{tabular}{cccc}
\hline Component & Material & $\begin{array}{c}\text { Maximum Limit } \\
\text { Temperature }\left({ }^{\circ} \mathbf{C}\right)\end{array}$ & $\begin{array}{c}\text { Temperature } \\
\text { Measured }\left({ }^{\circ} \mathbf{C}\right)\end{array}$ \\
\hline $\begin{array}{c}\text { Cover } \\
\text { Heatsink }\end{array}$ & PC & 145 & 90 \\
Equipment carrier & Aluminum & 460 & 131 \\
Equipment & PA66-30FV & 150 & 97 \\
Drivers Bases & PA66-30FV & 150 & 129 \\
Driver (Electronic) & Aluminum & 460 & 130 \\
Diffuser & Silicon (Weakest) & 150 & 130 \\
Chassis & PC & 145 & 118 \\
PCB & PA66-30FV & 150 & 123 \\
\hline
\end{tabular}

Table 5. Maximum temperature limit of the material versus temperature measured in the different parts of the Model at $-10{ }^{\circ} \mathrm{C}$. Source: our own elaboration.

\begin{tabular}{cccc}
\hline Component & Material & $\begin{array}{c}\text { Maximum Limit } \\
\text { Temperature }\left({ }^{\circ} \mathbf{C}\right)\end{array}$ & $\begin{array}{c}\text { Temperature } \\
\text { Measured }\left({ }^{\circ} \mathbf{C}\right)\end{array}$ \\
\hline Cover & PC & 145 & 42 \\
Heatsink & Aluminum & 460 & 82 \\
Equipment carrier & PA66-30FV & 150 & 47 \\
Equipment & PA66-30FV & 150 & 83 \\
Drivers Bases & Aluminum & 460 & 84 \\
Driver (Electronic) & Silicon (Weakest) & 150 & 90 \\
Diffuser & PC & 145 & 69 \\
Chassis & PA66-30FV & 150 & 74 \\
PCB & Aluminum & 460 & 88 \\
\hline
\end{tabular}

In the next Figures 14-16, a comparison of some of the different components of the Model and for the different ambient temperatures of the simulations is shown, giving the range of temperatures at which, the components are located. 

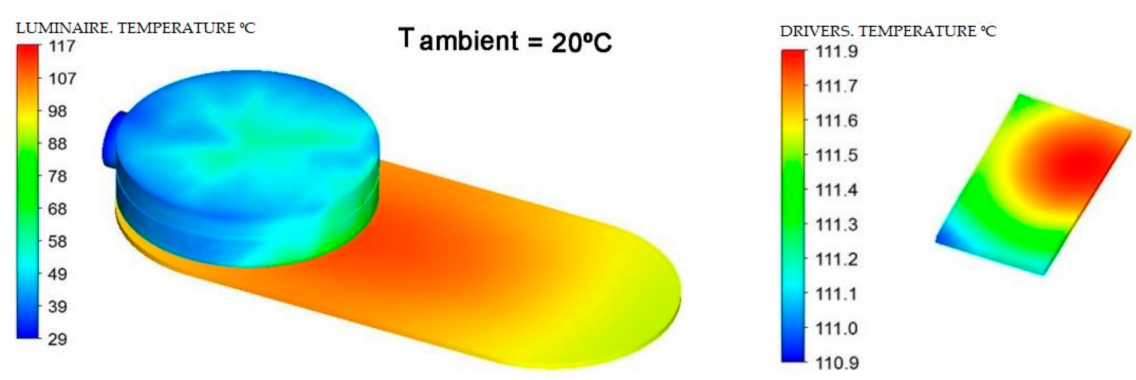

T ambient $=20^{\circ} \mathrm{C}$
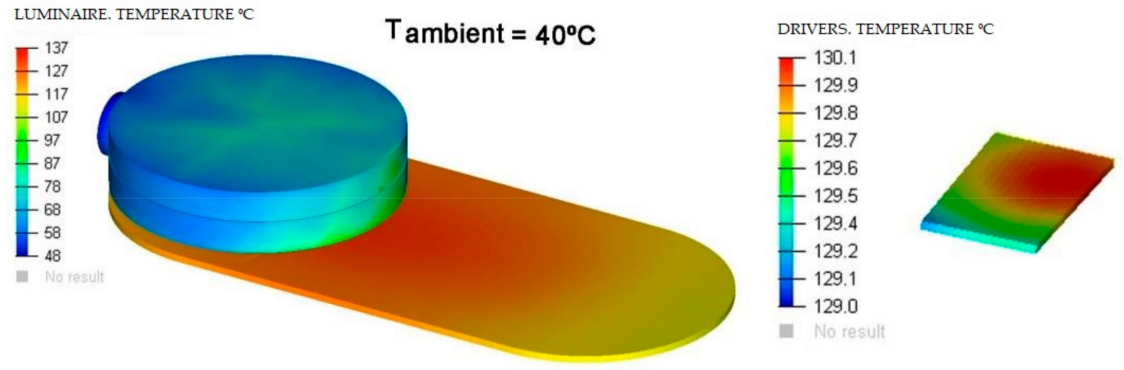

Tambient $=40^{\circ} \mathrm{C}$
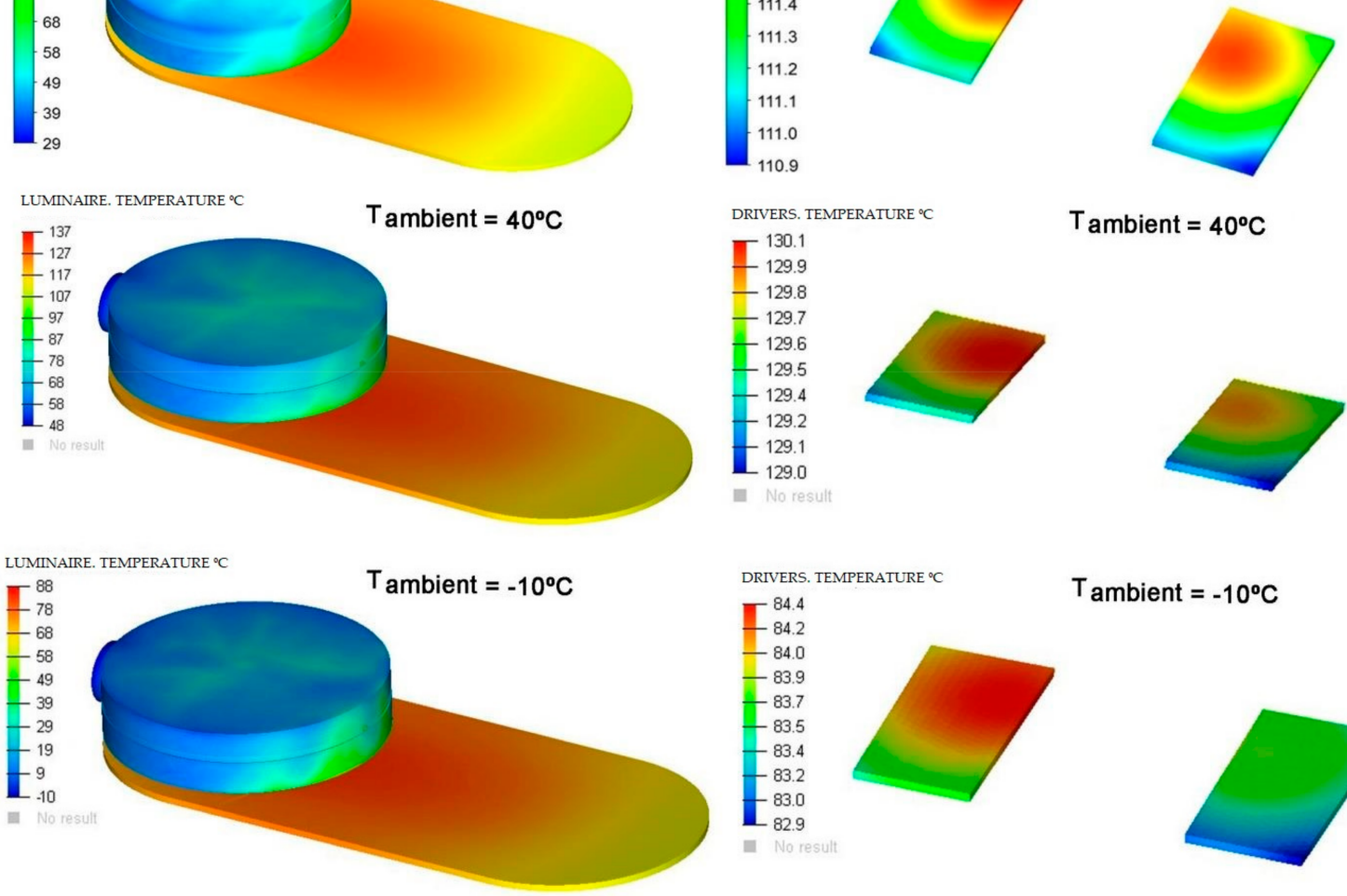

Tambient $=-10^{\circ} \mathrm{C}$

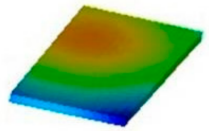

Figure 14. Temperature range of the complete luminaire and of the drivers base with respect to the ambient temperature in each simulation. Source: our own elaboration.

\section{Complete luminaire}

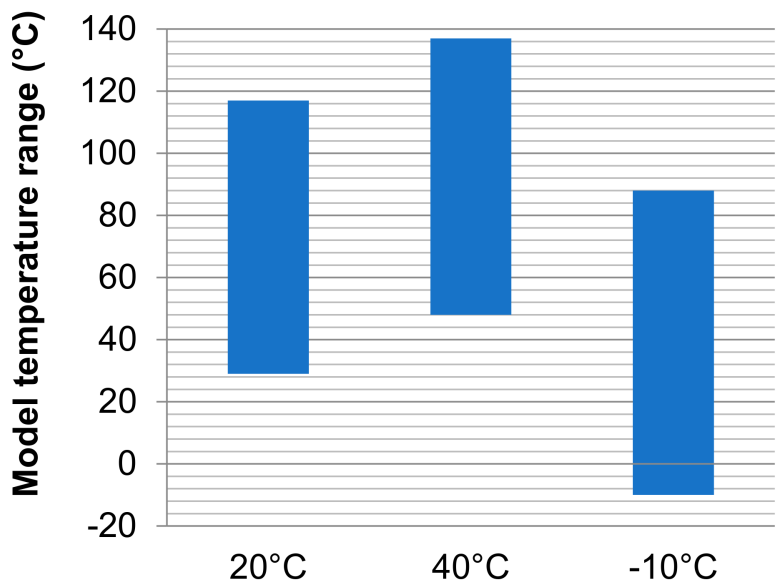

Ambient or contour temperature of the simulation $\left({ }^{\circ} \mathrm{C}\right)$

\section{DRIVERS}

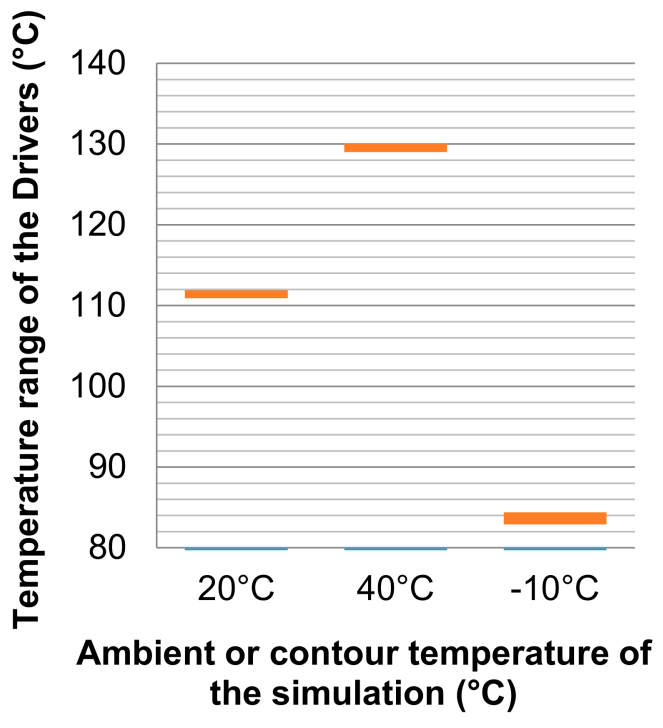

(b)

Figure 15. Temperature range of the complete luminaire (a) and of the drivers base (b) with respect to the ambient temperature in each simulation. Source: our own elaboration. 

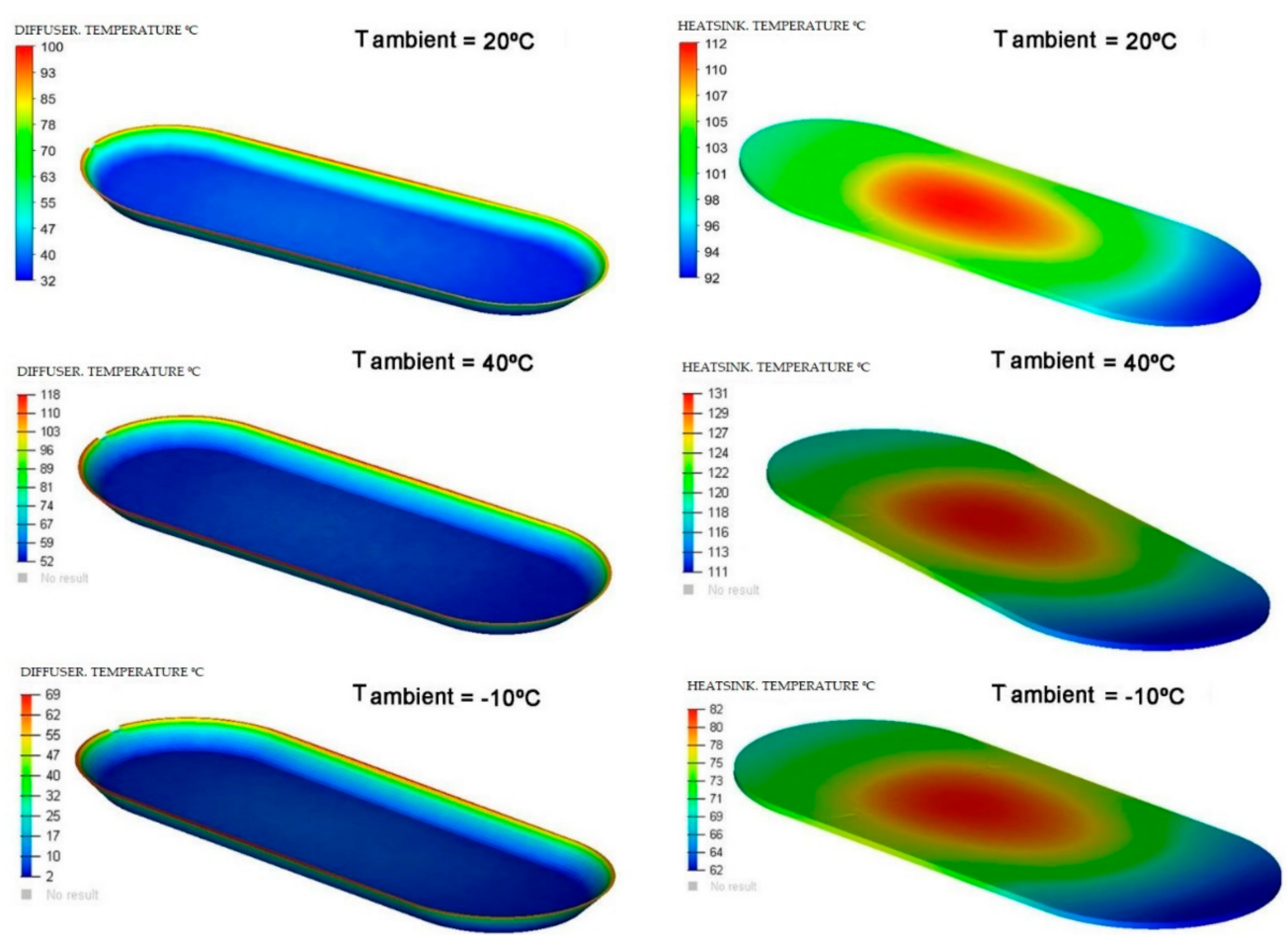

Figure 16. Comparison of dissipation of the diffuser (left) and of the heatsink (right) for different simulation temperatures. Source: our own elaboration from the software HyperView.

The heatsink is made of aluminum and has a limit temperature of $460^{\circ} \mathrm{C}$. The maximum temperature reached by the heatsink in the simulations is much lower than the limit temperature. The diffuser is composed of PC (polycarbonate), a material that has an operating limit temperature of $145^{\circ} \mathrm{C}$. The results of the simulations show that the maximum temperatures of these components are within operating temperature range, as shown in Figure 17.

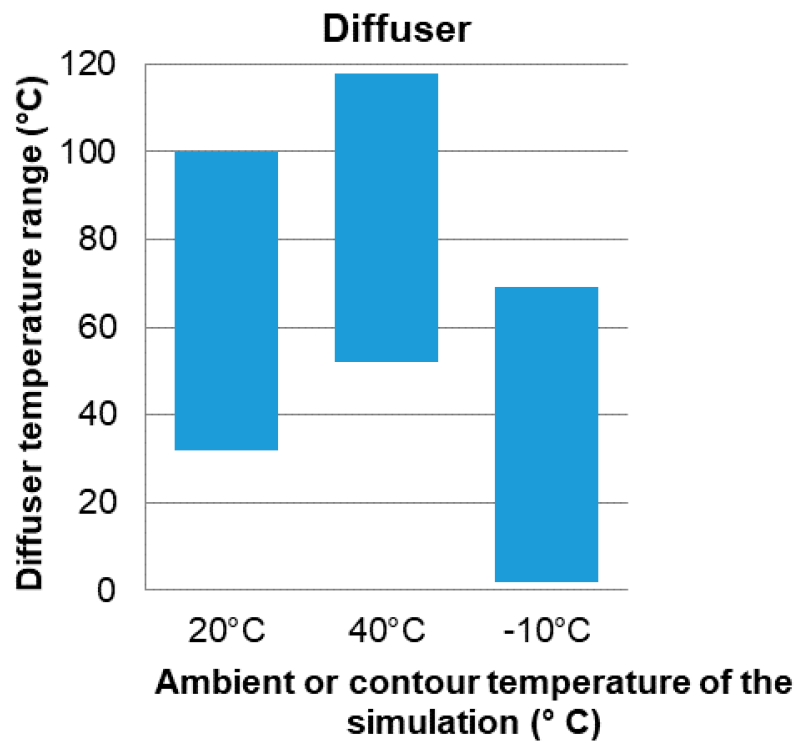

(a)

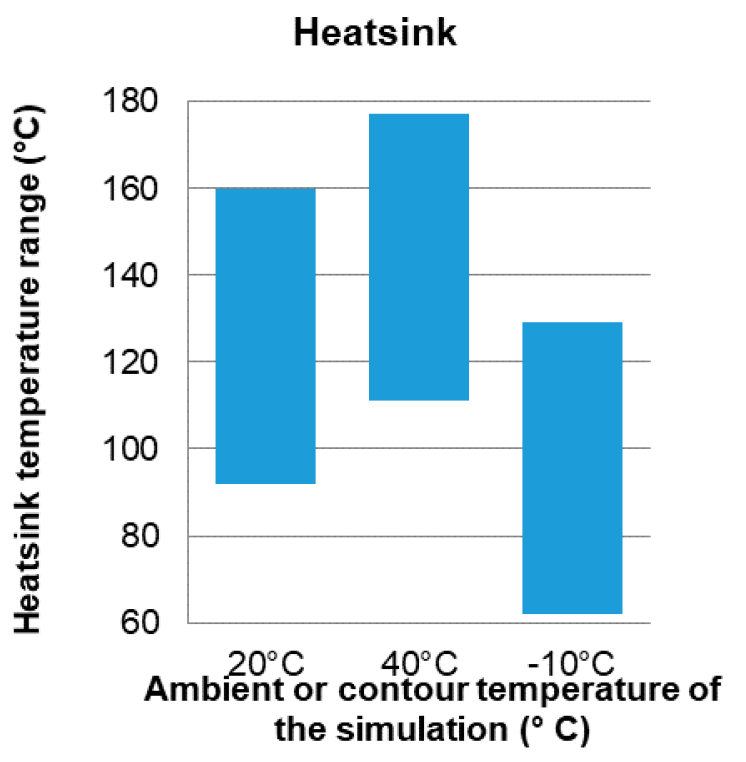

(b)

Figure 17. Temperature range of the diffuser (a) and the dissipater or heatsink (b) with respect to the ambient temperature in each simulation of the Model. Source: our own calculations. 


\subsection{Experimental Results}

The prototype high-power LED luminaire was built with the same geometry and dimensions than the model in order to validate the simulation. This luminaire corresponds to Air Series 7 of ATP lighting (Figure 18).

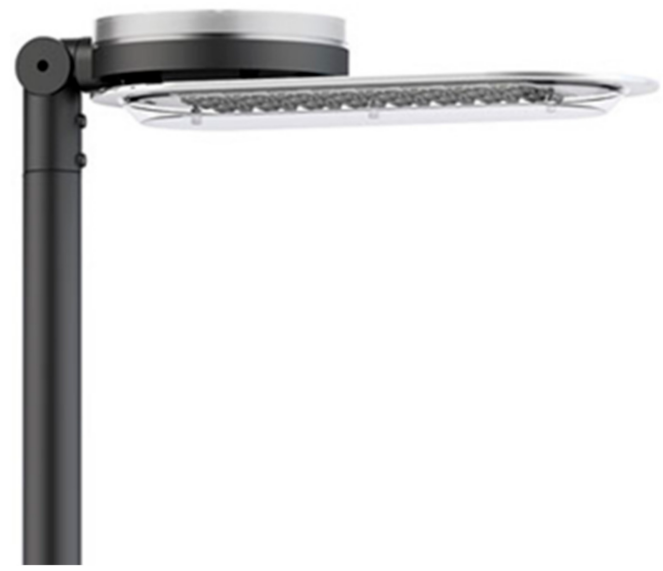

Figure 18. Luminaire Model. LED Air Series 7 of ATP Lighting. Source: ATP LED catalog lighting.

In the following Tables 6 and 7, the main power characteristics of LED and driver features are collected.

Table 6. Luminaire power table. Source: manufacturer's data.

\begin{tabular}{ccccc}
\hline Model & Nominal Power $(W)$ & Number of LEDs & Power by LED (W/LED) & Power DRIVER (W) \\
\hline ATP Aire Serie 7 & 204 & 96 & 2 & $12(6 \mathrm{~W} /$ driver $)$ \\
\hline
\end{tabular}

Table 7. Driver features. Source: manufacturer's data.

\begin{tabular}{cccccc}
\hline Model & Efficiency (\%) & Nominal Power (W) & Operating Input Range (V) & Storage Temperature $\left({ }^{\circ} \mathbf{C}\right)$ & Output Current (A) \\
\hline MP4688 & 95 & $2-2.5$ & $4.5-80$ & -65 to 150 & Up to 1 A \\
\hline
\end{tabular}

The drivers used for control LEDs is the chip MP4688 high power control LEDs. The luminaire has two drivers PCB, and each driver PCB has three MP4688. Each integrated MP4688 controls 16 LEDs (96 LEDs in the luminaire).

Each MP4688 has nominal power of $2 \mathrm{~W}$. As we have a nominal power of $2 \mathrm{~W}$, two drivers PCB and three chips in each PCB, we have a total value of $12 \mathrm{~W}$ (total power drivers).

For the acquisition of real thermal dissipation data of the analyzed luminaire, a thermographic camera was used at a stabilized temperature of $20^{\circ} \mathrm{C}$ and in a climatized environment with a relative humidity of $70 \%$ and air speed of $0 \mathrm{~m} / \mathrm{s}$.

The thermal imaging camera used was the FLUKE Ti 25 model. It captures a digital image with an infrared and fuses it. The temperature range is $-20{ }^{\circ} \mathrm{C}$ to $350{ }^{\circ} \mathrm{C}$ with a precision of $\pm 2{ }^{\circ} \mathrm{C}$. The thermal sensitivity is $0.1^{\circ} \mathrm{C}$ at an ambient temperature of $20^{\circ} \mathrm{C}$, which describes the smallest difference between two pixels in temperature that the camera can measure (Table 8). 
Table 8. Table of specifications of the thermal imager. Source: the user's manual of the Ti 25 FLUKE thermal camera.

\begin{tabular}{cc}
\hline Attribute & Value \\
\hline Thermal sensitivity & $\leq 90 \mathrm{mK}$ \\
Temperature Measurement Range & $-20 \rightarrow+350{ }^{\circ} \mathrm{C}$ \\
Maximum Accuracy of Temperature & $\pm 2{ }^{\circ} \mathrm{C}$ \\
Measurement & $23 \times 17^{\circ}$ \\
Field of vision $\mathrm{H} \times \mathrm{V}$ & $9 \mathrm{~Hz}$ \\
Update frequency & 15 (Thermal Lens) $\mathrm{cm}, 46$ (Visual Lens) cm \\
Minimum Focus Distance & Manual \\
Type of Focus & $160 \times 120$ pixel \\
Detector Resolution & 3.7 plg \\
Display size & $640 \times 480$ pixel \\
Display Resolution & Ti25 \\
Model number &
\end{tabular}

A fundamental parameter when acquiring images with the thermal imaging camera is the emissivity. All objects radiate infrared energy. The amount of energy radiated is based on two main factors: the surface temperature of the object and the emissivity of said surface. Emissivity is a very important issue for measuring surface temperature without being in contact [39]. Depending on the material to be measured, the emissivity varies [40]. The emissivity determined to obtain the temperatures of the materials was obtained from a table of emissivities.

A progressive data collection was made from the ignition to the thermal stabilization of the equipment, taking data periodically until the temperature remained stable.

To take the measurements, the dissipater and diffuser with the thermal imager and to be a specific material with a specific alloy or formulation in the material compound, several types of emissivities were used to obtain the exact temperature (Figures 19-22).

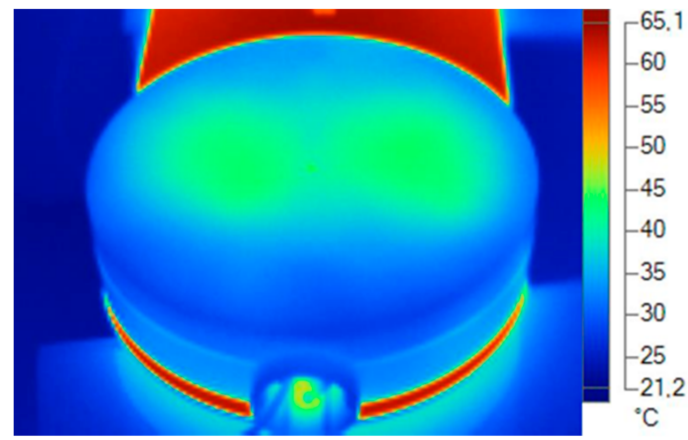

Figure 19. Thermal data of the cover. Blue and green area. Plastic emissivity 0.92 . Source: Software SmartView 4.1 Fluke.

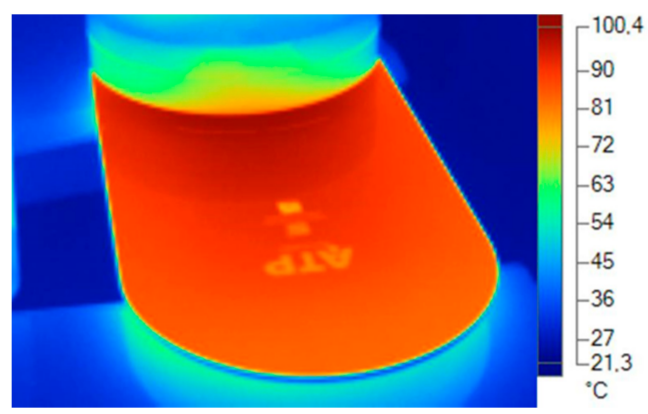

Figure 20. Thermal data of the heatsink. Reddish area: emissivity aluminum alloy 0.5. Source: Software SmartView 4.1 Fluke. 


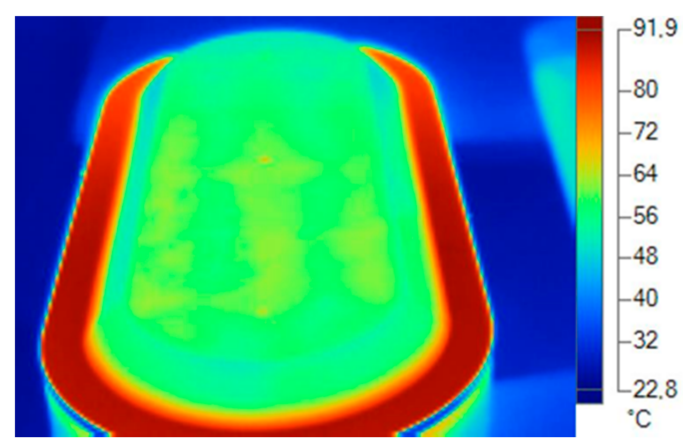

Figure 21. Thermal data of the heatsink. Reddish area: emissivity aluminum alloy 0.5. Source: Software SmartView 4.1 Fluke.

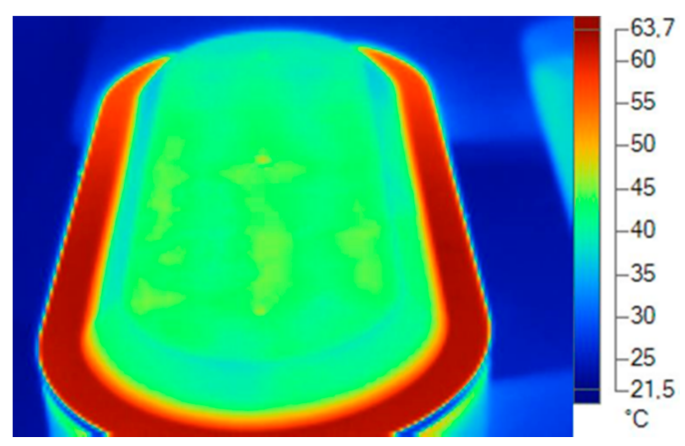

Figure 22. Thermal data of the diffuser. Green zone: plastic emissivity 0.92. Source: Software SmartView 4.1 Fluke.

\section{Discussion}

Once the simulation was validated at $20^{\circ} \mathrm{C}$ in the laboratory, an analysis of the junction temperature of the LEDs $\left(T_{j}\right)$ is carried out in order to study how it affects the lighting performance.

To ensure the useful life, efficiency and color of the LEDs, the junction temperature of the LEDs must be maintained in a specific range.

After obtaining the junction temperature of the LEDs in the simulations for the different boundary conditions that surround the luminaire, such as $40{ }^{\circ} \mathrm{C}, 20{ }^{\circ} \mathrm{C}$ and $-10{ }^{\circ} \mathrm{C}$, they are compared with the LED junction temperatures found in the market (Table 9 , Figures 23 and 24).

Table 9. Junction temperatures of the LEDs obtained in the simulations $\left(T_{j}\right)$. Source: our own elaboration.

\begin{tabular}{ccc}
\hline & $\begin{array}{c}\text { External Ambient Temperature of the } \\
\text { Simulation }\left({ }^{\circ} \mathbf{C}\right)\end{array}$ & $\begin{array}{c}\text { Junction Temperature of the } \\
\text { LEDs } \mathbf{T}_{\mathbf{j}}\left({ }^{\circ} \mathbf{C}\right)\end{array}$ \\
\hline Temperature 1 & 40 & 135 \\
Temperature 2 & 20 & 117 \\
Temperature 3 & -10 & 86 \\
\hline
\end{tabular}




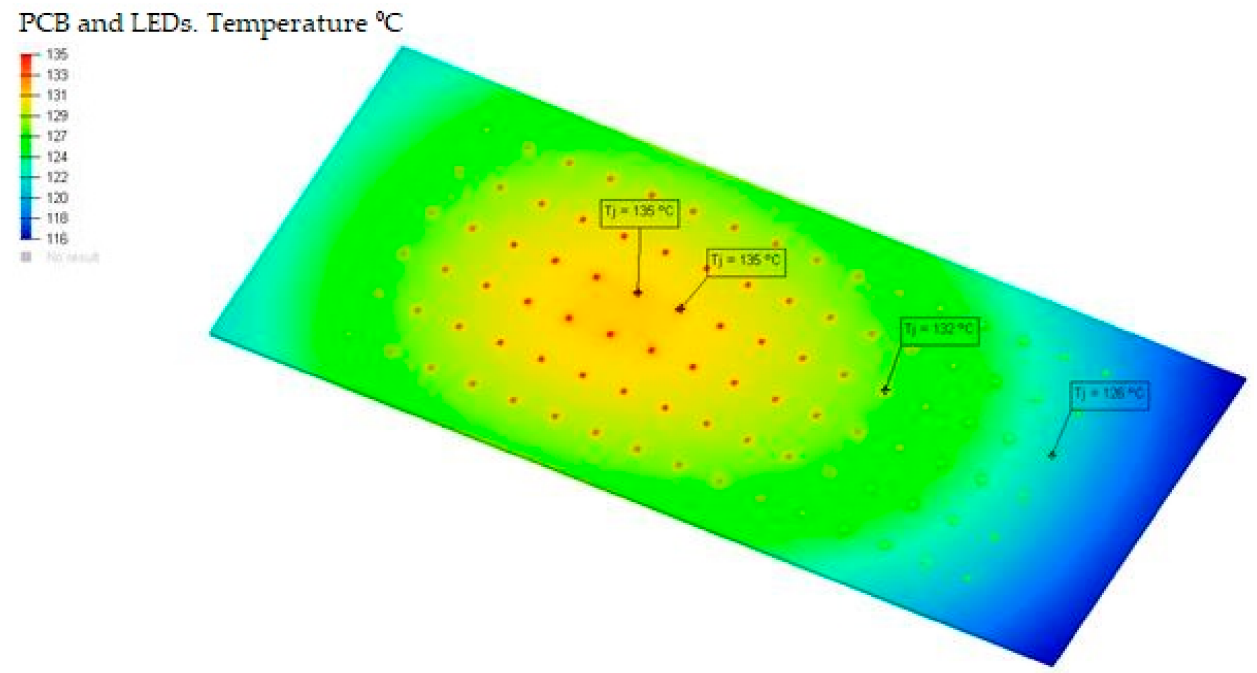

Figure 23. Summary of the joining temperatures of LEDs during the simulation at ambient temperature of $40^{\circ} \mathrm{C}$. Source: our own elaboration.

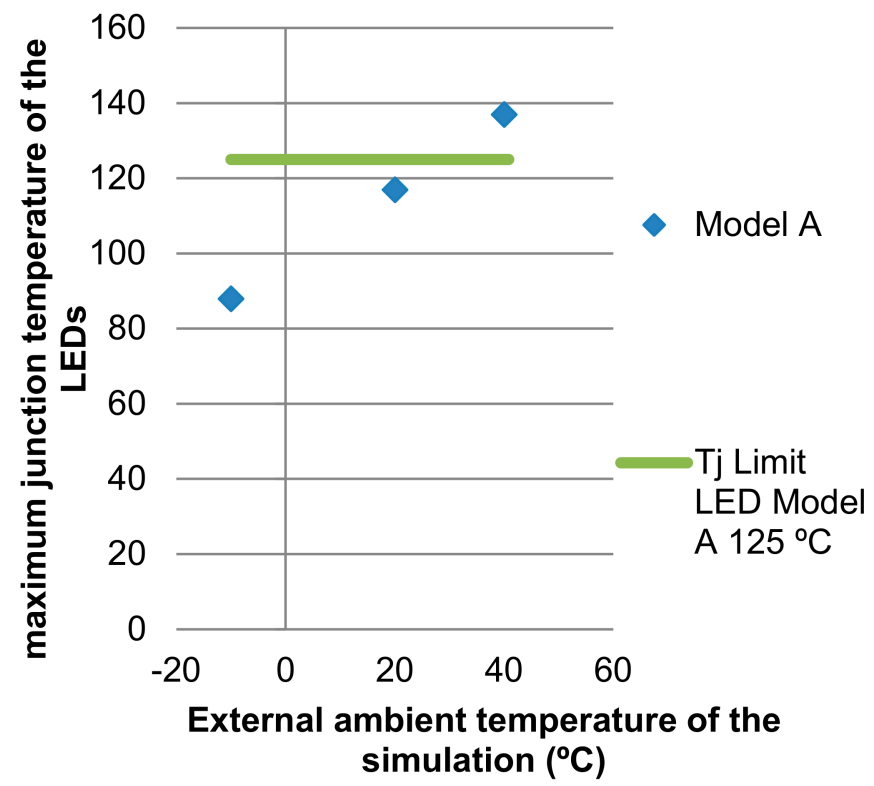

Figure 24. Variation of the maximum junction temperature of the LEDs with respect to the ambient temperature of the simulation, marking the limit junction temperature of each LED. Source: our own elaboration.

For the Model, an Osram LUW CQAR LED (streetwhite) with its respective data sheet was used. It was chosen to take note of the dimensions of the LED with the power of $2 \mathrm{~W} / \mathrm{LED}$ and, therefore, have an orientation for the features. The maximum junction temperature of this LED corresponds to a temperature of $135^{\circ} \mathrm{C}$. In this luminaire, the maximum temperature reached is $10^{\circ} \mathrm{C}$ above the value of the temperature of the LED junction, which causes a decrease in lamp life, possibly causing the LED light output to decrease irreversibly in the long term at a faster rate than at lower temperatures [41]. Controlling the temperature of LEDs is, therefore, one of the most important aspects of the optimal performance of LED systems [1].

In the following graphs, it can be observed how important LED parameters vary with the junction temperature that are included in the data sheet provided by the manufacturer. Figure 25 shows how the luminous flux decays as the bonding temperature increases. For the junction temperature at the ambient temperature of $20^{\circ} \mathrm{C}$, which is $117^{\circ} \mathrm{C}$, the LEDs 
have a $20 \%$ decrease in luminous flux. By increasing the LED junction temperature, the power that is perceived as light by the human eye decreases.

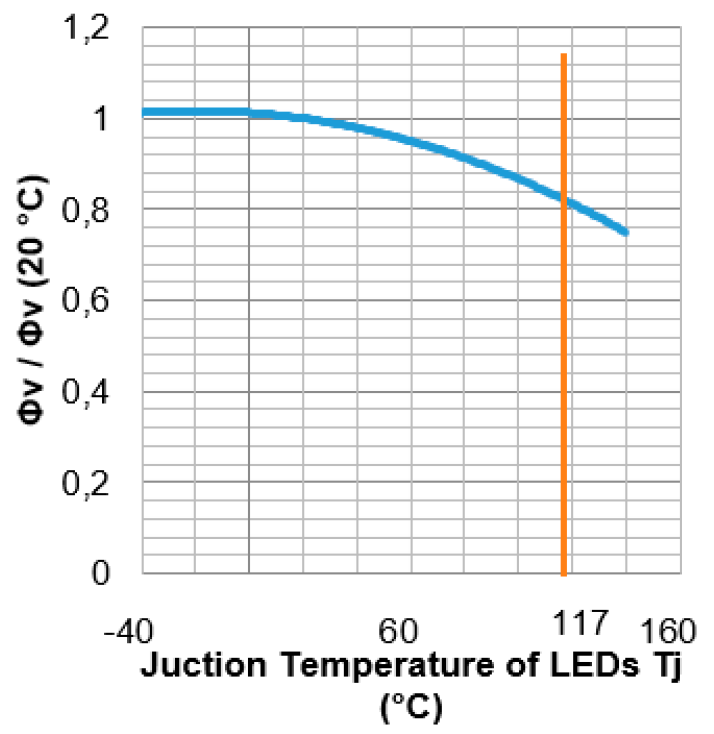

\section{Relative luminous flux}

$\Phi_{V} / \Phi_{V}\left(20^{\circ} \mathrm{C}\right)=f\left(T_{j}\right)$

Figure 25. Junction temperature of LEDs (Tj) vs. luminous flux. Source: our own elaboration and data sheet LED Osram LUW CQAR (streetwhite).

Figure 26 shows the variation of the chromaticity coordinates with respect to the change in the junction temperature. For the junction temperature at the ambient temperature of $20^{\circ} \mathrm{C}$ at which the LEDs of the Model are located (green line of Figure 26), the variation of the chromaticity coordinates is shown.

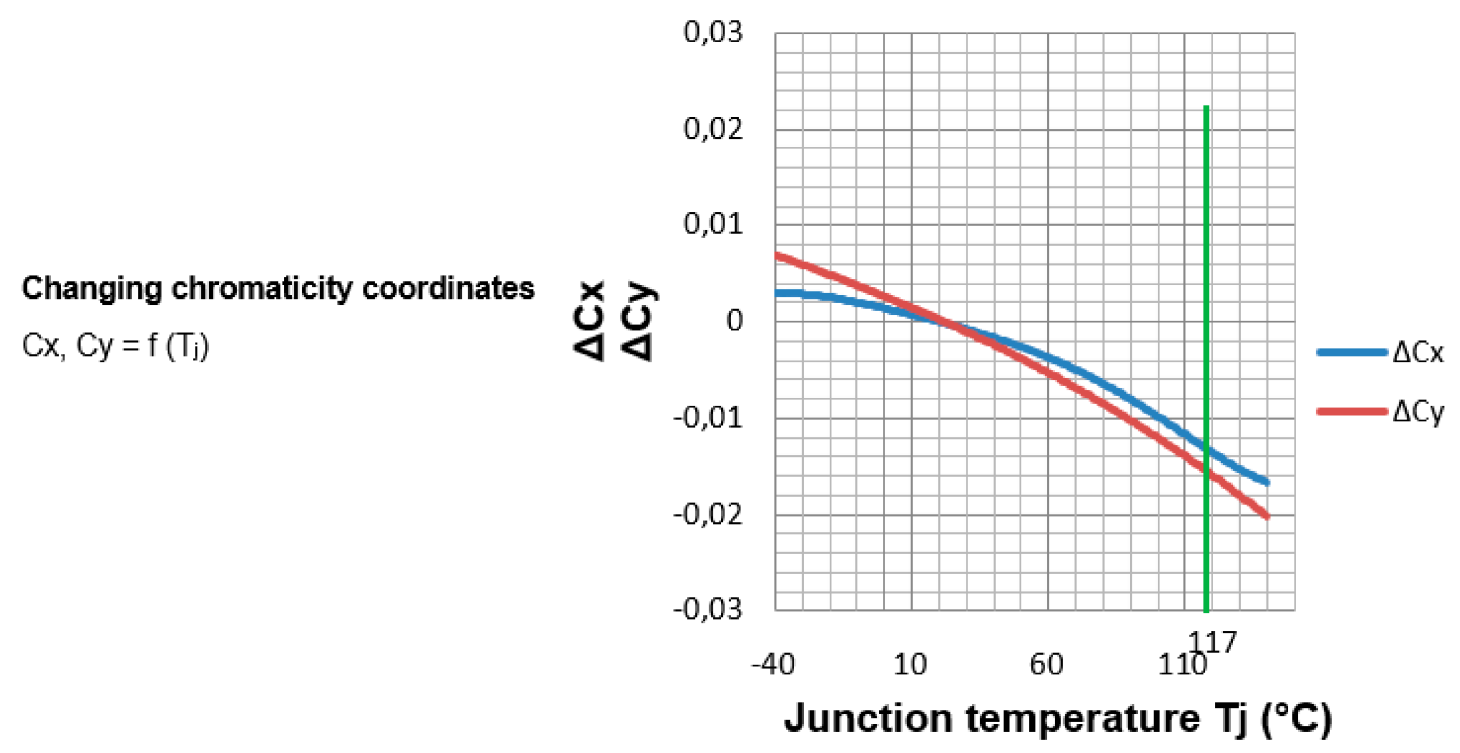

Figure 26. Junction temperature (Tj) vs. change of chromaticity coordinates. Source: our own elaboration and data sheet LED Osram LUW CQAR (streetwhite).

The variation of the junction temperature of the LED causes the chromaticity coordinates to change. We observed how the color quality of the light becomes worse. For the junction temperature corresponding to $20^{\circ} \mathrm{C}$ ambient temperature, which is $117^{\circ} \mathrm{C}$, the variation of chromaticity varies causing a decrease in the color quality of the LED light, moving in the chromaticity diagram around $15 \%$. 
The theoretical and experimental data vary very slightly comparatively in Figure 27. In this way, we can verify that, from simulation techniques, we can obtain a very real approximation to the operating results of the Model without the need to build the prototype. The thermal dissipation simulation techniques allow to obtain very precise information, always linked to the precision of the geometry of the design and the materials, as fundamental for the results to be as accurate as possible.

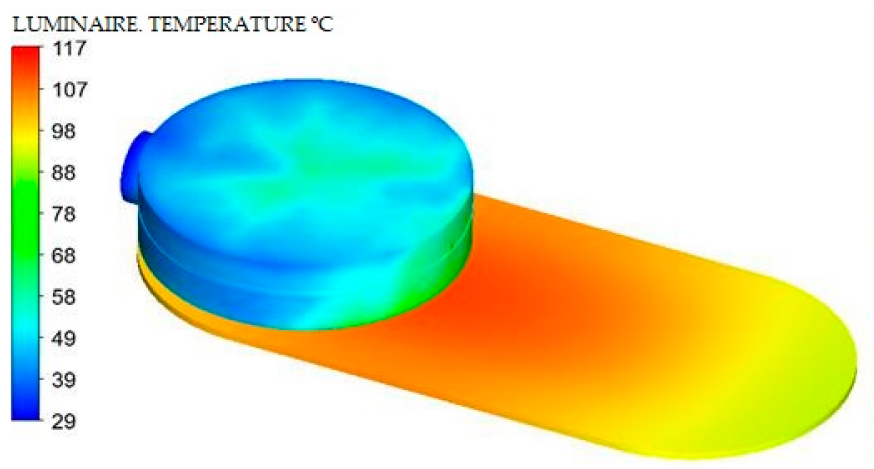

LUMINAIRE. TEMPERATURE ${ }^{\circ} \mathrm{C}$
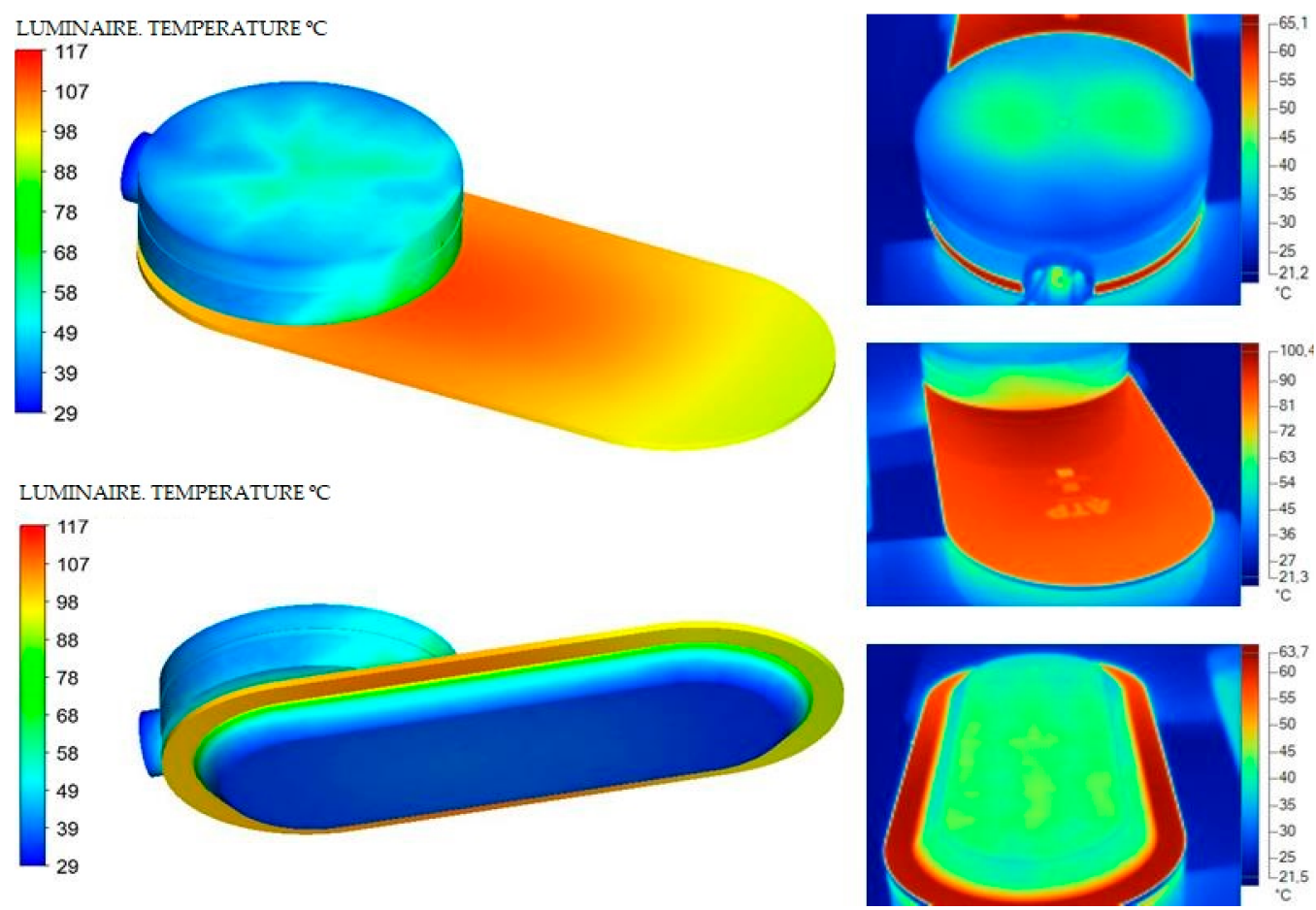

Figure 27. Comparative theoretical data (left) and experimental data (right). Source: our own elaboration from the software HyperView and SmartView 4.1.

At the time of favoring heat dissipation, the dissipater is the most important component to reduce the binding temperature. Most heatsinks are designed with fins to increase their contact surface with air and dissipate more heat [42]. It is necessary to improve the design of the components of the luminaire to facilitate the dissipation of heat and favor the passage of air through the heatsink of the luminaires to lower the temperature of electronic devices. To improve cooling, auxiliary ventilation systems could be incorporated, to improve the flow of air from the interior to the exterior.

A major problem with high power LED luminaires is the heat generated inside. The distribution of the LEDs and the effect of the number of LEDs lit affect the junction temperature and strongly participate in the degradation of the LED [43]. Most luminaires contain aluminum heatsinks as a solution. Currently, materials with new alloys and formulations for effective thermal dissipation are being investigated. For example, aluminum nitrate has been developed to be applied as a thin layer in the dissipaters, which has certain advantages over conventional dielectrics based on polymers or ceramic substrates, such as excellent thermal dissipation and low thermal resistance [44]. The issue of thermal dissipation is the order of the day; materials are being investigated to be used as heat sinks that promote greater durability of LEDs due to an improvement in thermal dissipation [45].

\section{Conclusions}

With this work, we intend to present an analytical methodology to calculate the thermal dissipation of LED luminaires, previously, in the design phase. The method was 
validated by comparing the results of the theoretical thermal simulations on the basis of a previously designed luminaire model with the experimental data obtained in the laboratory.

The proposed methodology allows the simulation to be carried out in the design phase of the LED luminaires, before launching into the construction phase of the prototype. This allows to analyze and experiment with the model in a virtual environment, reducing the time and cost requirements associated with the tests performed.

This study is aimed at the preliminary thermal analysis of LED luminaires, to verify the design and materials of the luminaires and to check the temperature of the LEDs and their impact in the face of the good functioning of light-emitting diodes. The study observes the influence of the junction temperature of the LEDs, as a critical issue of the design phase that can seriously affect the functionality of the luminaire and causes a decrease in the useful life and variation of the light properties of the LEDs, such as the decrease in luminous flux and change in chromaticity coordinates.

All electronic devices and circuits generate excess heat and require greater attention to avoid premature failures. LEDs convert $45 \%$ of the energy applied to light and the remaining 55\% into heat, which must be dissipated using a design and suitable materials so that the durability and properties of the LEDs are not affected by the increase in temperature [17].

The thermal simulations give the engineer information about the temperature and air flow inside the equipment, allowing engineers to design cooling systems to optimize design and reduce energy consumption, weight, and cost, and verifying that there are no problems when the equipment is built. In this work, we used thermal simulation software applying computational fluid dynamics (CFD) techniques to predict the temperature and air flow of an electronic system [34].

A good design of the luminaire, where the circulation of air is favored for the benefit of the dissipation of the junction temperature of the LEDs, favors the useful life and improves the lighting efficiency and reliability of the LEDs, which allows them to have better lighting properties. Apart from the design, a good selection of materials for the components of the luminaire where the thermal conductivity is high favors the thermal dissipation of the luminaire.

Addressing and trying to mitigate the LED fixture overheating issues associated with poor heat dissipation is key, as they end up affecting light quality, chromaticity, and color temperature, directly impacting the lifespan of luminaires and the health of users by altering circadian rhythms. That is why we consider it essential to design lighting equipment that allows high thermal dissipation [46]. This work proposes a methodology for the scientific researcher that satisfies the future need to design luminaires with LED technology that are sustainable for the environment, safe for human health, reliable and durable, supported by the proven results obtained.

Author Contributions: Conceptualization, M.J.H.-O. and J.d.D.U.-S.; methodology M.J.H.-O., M.J.H.O. and J.d.D.U.-S.; software, M.J.H.-O., M.J.H.-P. and J.d.D.U.-S.; validation, M.J.H.-O. and B.O.F.; formal analysis M.J.H.-O. and J.d.D.U.-S.; investigation, M.J.H.-O., M.J.H.-O. and J.d.D.U.-S.; resources, writing M.J.H.-O. and J.d.D.U.-S.; writing-review and editing, M.J.H.-O. and J.d.D.U.-S.; visualization M.J.H.-O. and J.d.D.U.-S. supervision, M.J.H.-O. and B.O.-F.; project administration, M.J.H.-O. and B.O.-F.; funding acquisition. All authors have read and agreed to the published version of the manuscript.

Funding: This research received no external funding.

Institutional Review Board Statement: Not applicable.

Informed Consent Statement: Not applicable.

Data Availability Statement: We accept MDPI Research Data Policies Section at https:/ /www.mdpi. com/ethics (accessed on 26 November 2021).

Conflicts of Interest: The authors declare no conflict of interest. 


\section{References}

1. Gago-Calderón, A.; Hermoso-Orzáez, M.J.; De Andres-Diaz, J.R.; Redrado-Salvatierra, G. Evaluation of uniformity and glare improvement with low energy efficiency losses in street lighting LED luminaires using laser-sintered polyamide-based diffuse covers. Energies 2018, 11, 816. [CrossRef]

2. Li, R.; Liu, Q.; Huang, L.; Yin, L.; Song, G. Properties of Thermal Interface Materials and Its Impact on Thermal Dissipation and Reliability of LED Automotive Lighting. In Proceedings of the 2018 15th China International Forum on Solid State Lighting: International Forum on Wide Bandgap Semiconductors China, SSLChina: IFWS 2018, Shenzhen, China, 15 October 2018; IEEE: Shenzhen, China, 2018; pp. 154-157.

3. Tsai, C.C.; Cheng, W.C.; Chang, J.K.; Huang, S.Y.; Liou, J.S.; Chen, G.H.; Huang, Y.C.; Wang, J.S.; Cheng, W.H. Thermal-Stability Comparison of Glass- and Silicone-Based High-Power Phosphor-Converted White-Light-Emitting Diodes Under Thermal Aging. IEEE Trans. Device Mater. Reliab. 2012, 14, 4-8. [CrossRef]

4. Pauley, S. Lighting for the Human Circadian Clock. Recent Research Indicates That Lighting Has Become a Public Health Issue. Med. Hypotheses 2004, 63, 588-596. [CrossRef] [PubMed]

5. Dettweiler, U.; Becker, C.; Auestad, B.H.; Simon, P.; Kirsch, P. Stress in School. Some Empirical Hints on the Circadian Cortisol Rhythm of Children in Outdoor and Indoor Classes. Int. J. Environ. Res. Public Health 2017, 14, 475. [CrossRef]

6. Ritonja, J.; McIsaac, M.A.; Sanders, E.; Kyba, C.; Grundy, A.; Cordina-Duverger, E.; Spinelli, J.J.; Aronson, K.J. Outdoor light at night at residences and breast cancer risk in Canada. Eur. J. Epidemiol. 2020, 35, 579-589. [CrossRef] [PubMed]

7. Dominoni, D.M.; Borniger, J.C.; Nelson, R.J. Light at night, clocks and health: From humans to wild organisms. Biol. Lett. 2016, 12, 2-5. [CrossRef]

8. Richard, G.; Stevens, P.; George, C.; Brainard, P.; David, E.; Blask, M.; Steven, W.; Lockley, P.; Mario, E.; Motta, M. Adverse Health Effects of Nighttime Lighting Comments on American Medical Association Policy Statement. Am. J. Prev. Med. 2013, 45, 343-346. [CrossRef]

9. Cajochen, C.; Frey, S.; Anders, D.; Späti, J.; Bues, M.; Pross, A.; Mager, R.; Wirz-Justice, A.; Stefani, O. Evening exposure to a light-emitting diodes (LED)-backlit computer screen affects circadian physiology and cognitive performance. J. Appl. Physiol. 2011, 110, 1432-1438. [CrossRef]

10. Chen, H.T.; Tan, S.C. Color Variation Reduction of GaN-Based White Light-Emitting Diodes Via Peak-Wavelength Stabilization. IEEE Trans. Power Electron. 2013, 29, 3709-3719. [CrossRef]

11. Zhang, Y.; Long, E.; Zhang, M. A New Thermal Interface Material: Graphene-epoxy Composite used for LED Heat Dissipation. Chiang Mai J. Sci. 2018, 45, 2459-2470.

12. Min, J.; Min, K. Journal of A ff ective Disorders Outdoor light at night and the prevalence of depressive symptoms and suicidal behaviors: A cross-sectional study in a nationally representative sample of Korean adults. J. Affect. Disord. 2018, 227, 199-205. [CrossRef]

13. Cho, Y.; Ryu, S.-H.; Lee, B.R.; Kim, K.H.; Lee, E.; Choi, J. Effects of artificial light at night on human health: A literature review of observational and experimental studies applied to exposure assessment. Chronobiol. Int. J. Biol. Med. Rhythm. Res. 2015, 32, 1294-1310. [CrossRef]

14. Hsu, C.N.; Tain, Y.L. Light and circadian signaling pathway in pregnancy: Programming of adult health and disease. Int. J. Mol. Sci. 2020, 21, 2232. [CrossRef]

15. Liu, Y.; Mou, T. Evaluation of Window Lighting Considering the Circadian Effect. In Proceedings of the CIE Centenary Conference towards a New Century of Light, Paris, France, 15-16 April 2013; pp. 851-856.

16. Delendik, K.; Kolyago, N.; Voitik, O. Design and investigation of cooling system for high-power LED luminaire. Comput. Math. Appl. 2021, 83, 84-94. [CrossRef]

17. Sun, L.; Zhu, J.; Wong, H. Simulation and evaluation of the peak temperature in LED light bulb heatsink. Microelectron. Reliab. 2016, 61, 140-144. [CrossRef]

18. Shin, H.W.; Jung, S.B.; Lee, H.S. Thermal Resistance Analysis of Light-Emitting Diode Modules with Thermal Via Structure. J. Electron. Mater. 2018, 47, 7323-7330. [CrossRef]

19. Cai, M.; Liang, Z.; Tian, K.M.; Yun, M.H.; Zhang, P.; Yang, D.G.; Zhang, G.Q. Junction Temperature Prediction for LED Luminaires Based on a Subsystem-Separated Thermal Modeling Method. IEEE Access 2019, 7, 119755-119764. [CrossRef]

20. Şevik, S.; Abuşka, M.; Özdilli, Ö. Thermal performance analysis of a novel linear LED housing with inner and outer fins. Int. Commun. Heat Mass Transf. 2020, 119, 104970. [CrossRef]

21. Chakravarthii, D.M.K.; Devarajan, M.; Choo, C.L.; Suvindraj, K. Thermal and Optical Performance of LEDs Mounted on Substrates With Converging-Diverging and Diverging-Converging Channels. IEEE Trans. Compon. Packag. Manuf. Technol. 2018, 8, 1381-1390. [CrossRef]

22. Chen, H.; Lin, S.; Xiong, C. Analysis and Modeling of Thermal Effect and Optical Characteristic of LED Systems with Parallel Plate-Fin Heatsink. IEEE Photonics J. 2017, 9, 1-11. [CrossRef]

23. Hsieh, J.; Lin, D.; Cheng, C.; Kingkaew, S. The optimal design of the thermal spreading on high power LEDs. Microelectron. J. 2014, 45, 904-909. [CrossRef]

24. Sokmen, K.; Yuruklu, E.; Yamankaradeniz, N. Computational thermal analysis of cylindrical fin design parameters and a new methodology for defining fin structure in LED automobile headlamp cooling applications. Appl. Therm. Eng. 2016, 94, 534-542. [CrossRef] 
25. Hermoso-Orzáez, M.J.; Lozano-Miralles, J.A.; Lopez-Garcia, R.; Brito, P. Environmental Criteria for Assessing the Competitiveness of Public Tenders with the Replacement of Large-Scale LEDs in the Outdoor Lighting of Cities as a Key Element for Sustainable Development: Case Study Applied with PROMETHEE Methodology. Sustainability 2019, 11, 5982. [CrossRef]

26. Jeon, G.W.; Seung-Taek, O.; Lim, J.H. Natural Light Property-Based LED Lighting System to Maintain Human Circadian Rhythm. IOP Conf. Ser. Mater. Sci. Eng. 2019, 630, 012019. [CrossRef]

27. Rea, M.S. Human Health and Well-Being: Promises for a Bright Future from Solid-State Lighting. In Proceedings of the SPIE 7954, Light-Emitting Diodes: Materials, Devices, and Applications for Solid State Lighting XV; SPIE: San Francisco, CA, USA, 2011 ; p. 795404.

28. Shahzad, K.; Čuček, L.; Sagir, M.; Ali, N.; Rashid, M.I.; Nazir, R.; Nizami, A.S.; Al-Turaif, H.A.; Ismail, I.M.I. An ecological feasibility study for developing sustainable street lighting system. J. Clean. Prod. 2018, 175, 683-695. [CrossRef]

29. Lozano-Miralles, J.A.; Hermoso-Orzáez, M.J.; Gago-Calderón, A.; Brito, P. LCA case study to LED outdoor luminaries as a circular economy solution to local scale. Sustainability 2020, 12, 190. [CrossRef]

30. Anithambigai, P.; Chakravarthii, M.K.D.; Mutharasu, D.; Huong, L.H.; Zahner, T.; Lacey, D.; Kamarulazizi, I. Potential thermally conductive alumina filled epoxy composite for thermal management of high power LEDs. J. Mater. Sci. Mater. Electron. 2017, 28, 856-867. [CrossRef]

31. Lu, L.; Zhang, Z.; Guan, Y.; Zheng, H. Enhancement of Heat Dissipation by Laser Micro Structuring for LED Module. Polymers 2018, 10, 886. [CrossRef]

32. Analysis, A. Power Quality and Energy Efficiency in the Pre-Evaluation of an Outdoor Lighting Renewal with Study and Amortization Analysis. Energies 2017, 10, 836. [CrossRef]

33. Yu, X.; Zhang, B.; Zhao, S.; Kao, Z.; Yang, S. Enhancement of Heat Dissipation in LED Using Graphene and Carbon Nanotubes. ECS J. Solid State Sci. Technol. 2018, 7, M153-M160. [CrossRef]

34. Lee, D.; Lee, J.; Cho, M.; Park, H.; Cha, Y. Influence of the Thermal Conductivity of Thermally Conductive Plastics on the Thermal Distribution of an Light-Emitting Diode Headlight for Vehicles. J. Nanosci. Nanotechnol. 2018, 18, 5904-5907. [CrossRef]

35. Macuzic, S.; Lukic, J.; Ruzic, D. Three-Dimensional Simulation of the McPherson Suspension System. Teh. Vjesn. Gaz. 2018, 25, 1286-1290. [CrossRef]

36. Nair, D.V.; Ghoshdastidar, P.S. A comparative study of 2-D and 3-D conjugate natural convection from a vertical rectangular fin array with multilayered base subjected to distributed high heat flux. Int. J. Heat Mass Transf. 2018, 121, 1316-1334. [CrossRef]

37. Zhou, J.; Huang, J.; Wang, Y.; Zhou, Z. Thermal distribution of multiple LED module. Appl. Therm. Eng. 2016, 93, 122-130. [CrossRef]

38. Vera Coello, M.; Iglesias Estradé, I.; Sánchez Pérez, A.L.; Martínez Bazán, C. Ingeniería Fluidomecánica; Editorial Paraninfo: Madrid, Spain, 2012; ISBN 9788497329040.

39. Chen, H.Y.; Chen, C. Determining the emissivity and temperature of building materials by infrared thermometer. Constr. Build. Mater. 2016, 126, 130-137. [CrossRef]

40. Wen, C.-D.; Chai, T.Y. Experimental investigation of emissivity of aluminum alloys and application of multispectral radiation thermometry. Appl. Therm. Eng. 2011, 31, 2414-2421. [CrossRef]

41. Colaco, A.; Kurian, C.; Kini, S.; Colaco, S.; Johny, C. Thermal characterization of multicolor LED luminaire. Microelectron. Reliab. 2017, 78, 379-388. [CrossRef]

42. Karatekin, C.; Kökkaya, O. Comparative analysis of different cooling fin types for countering LED luminaires' heat problems Turk. J. Electr. Eng. Comput. Sci. 2018, 26, 454-466. [CrossRef]

43. Ben Abdelmlek, K.; Araoud, Z.; Ghnay, R.; Abderrazak, K.; Charrada, K.; Zissis, G. Effect of thermal conduction path deficiency on thermal properties of LEDs package. Appl. Therm. Eng. 2016, 102, 251-260. [CrossRef]

44. Hahn, B.D.; Kim, Y.; Ahn, C.W.; Choi, J.J.; Ryu, J.; Kim, J.W.; Yoon, W.H.; Park, D.S.; Yoon, S.Y.; Ma, B. Fabrication and characterization of aluminum nitride thick film coated on aluminum substrate for heat dissipation. Ceram. Int. 2016, 42, 18141-18147. [CrossRef]

45. Cho, E.C.; Huang, J.H.; Li, C.P.; Chang-Jian, C.W.; Lee, K.C.; Hsiao, Y.S.; Huang, J.H. Graphene-based thermoplastic composites and their application for LED thermal management. Carbon N. Y. 2016, 102, 66-73. [CrossRef]

46. Moon, S.M.; Kwon, S.Y.; Lim, J.H. Implementation of smartphone-based color temperature and wavelength control LED lighting system. Clust. Comput. 2016, 19, 949-966. [CrossRef] 